

\section{Effect of nutritional interventions with quercetin, oat hulls, $\beta$-glucans, lysozyme, and fish oil on immune competence related parameters of adult broilers}

\section{Authors}

M.M. van Krimpen ${ }^{1}$, M. Torki ${ }^{1}$, D. Schokker ${ }^{1}$, M. Lensing ${ }^{2}$, S. Vastenhouw ${ }^{1}$, F. M. de Bree ${ }^{4}$, A. Bossers ${ }^{4}$, N. de Bruijn ${ }^{3}$, A.J.M. Jansman ${ }^{1}$, J.M.J. Rebel ${ }^{1}$, and M.A. Smits ${ }^{1}$.

\footnotetext{
${ }^{1}$ Wageningen UR Livestock Research, Wageningen

${ }^{2}$ De Heus Animal Nutrition, Ede

${ }^{3} \mathrm{GD}$, Deventer

${ }^{4} \mathrm{CVI}$, Lelystad
}

This research was conducted by Wageningen Livestock Research, commissioned and funded by The Feed4Foodure program line "Nutrition, Intestinal Health, and Immunity" and partly funded by the Ministry of Economic Affairs (Policy Support Research project number BO-22.04-002-001)

Wageningen Livestock Research

Wageningen, September 2016 
M.M. van Krimpen, M. Torki, D. Schokker, M. Lensing, S. Vastenhouw, F.M. de Bree, A. Bossers, N. de Bruijn, A.J.M. Jansman, J.M.J. Rebel, and M.A. Smits, 2015. Effect of nutritional interventions with quercetin, oat hulls, $\beta$-glucans, lysozyme or fish oil on immune competence related parameters of adult broilers. Wageningen Livestock Research Report 977.

The purpose of this experiment was to evaluate the effects of five nutritional interventions, provided during d 14 - 28, including inclusion of a plant extract (quercetin); an insoluble fiber (oat hulls); a prebiotic ( $\beta$-glucan); an anti-microbial protein (lysozyme), and $\omega$ - 3 fatty acids from fish oil, on growth performance, composition of the intestinal microbiota, and morphology and gene expression of small intestine of broilers. Despite the different types of interventions, parameters related to immune competence were only marginally affected by the tested products. It seemed that in this study inclusion of oat hulls, and probably $\beta$-glucans, had perspective to improve immune competence. It is recommended to revaluate some of the tested interventions, especially dietary inclusion of oat hulls and $\beta$-glucans, in broilers starting from day-old onward.

This report can be downloaded for free at http://dx.doi.org/10.18174/390435 or at www.wur.nl/livestock-research (under Wageningen Livestock Research publications).

(C) 2016 Wageningen Livestock Research

P.O. Box 338, 6700 AH Wageningen, The Netherlands, T +31 (0)317 483953 ,

E info.livestockresearch@wur.nl, www.wur.nl/livestock-research. Wageningen Livestock Research is part of Wageningen University \& Research.

All rights reserved. No part of this publication may be reproduced and/or made public, whether by print, photocopy, microfilm or any other means, without the prior permission of the publisher or author.

The ISO 9001 certification by DNV underscores our quality level. All our research commissions are in line with the Terms and Conditions of the Animal Sciences Group. These are filed with the District Court of Zwolle. 


\section{Table of contents}

$\begin{array}{ll}\text { Foreword } & 5\end{array}$

$\begin{array}{lc}\text { Summary } & 6\end{array}$

1

$\begin{array}{ll}\text { Introduction } & 8\end{array}$

1.1 Immune competence and nutritional immunomodulation 8

1.2 Specific feed ingredients and omics techniques $\quad 8$

$\begin{array}{lll}1.3 & \text { Nutritional interventions } & 9\end{array}$

$2 \quad$ Material and methods $\quad 12$

$2.1 \quad$ Start date and end date of the experiment 12

2.2 Experimental facility and housing 12

2.2.1 Experimental animals 12

2.2.2 Climate $\quad 12$

$\begin{array}{ll}2.2 .3 \text { Light } & 13\end{array}$

$\begin{array}{ll}2.2 .4 \text { Health and Failure } & 13\end{array}$

$\begin{array}{ll}2.2 .5 \text { Vaccination } & 13\end{array}$

$\begin{array}{lll}2.3 & \text { Experimental measurements } & 13\end{array}$

2.3.1 Diets 13

2.3.2 Performance 14

2.3.3 Litter quality 14

2.3.4 Dissection and sample collection $\quad 14$

2.3.5 Microbiota 14

2.3.6 Genome-wide gene expression profiling 15

$\begin{array}{lll}2.4 & \text { Statistical analysis } & 16\end{array}$

$\begin{array}{llr}3 & \text { Results } & 17\end{array}$

$\begin{array}{lll}3.1 & \text { General } & 17\end{array}$

$\begin{array}{lll}3.2 & \text { Diets } & 17\end{array}$

$\begin{array}{lll}3.3 & \text { Performance } & 17\end{array}$

$\begin{array}{lll}3.4 & \text { Litter quality } & 19\end{array}$

$\begin{array}{llr}3.5 & \text { Microbiota } & 19\end{array}$

3.6 Gut morphology 23

$\begin{array}{lll}3.7 & \text { Gene expression } & 27\end{array}$

$\begin{array}{lll}3.8 & \text { Organ weights } & 28\end{array}$

Discussion 30

$\begin{array}{ll}\text { Conclusions } & 36\end{array}$

$\begin{array}{ll}\text { References } & \mathbf{3 7}\end{array}$

$\begin{array}{ll}\text { Appendix } 1 \text { Calculated composition of the diets } & 48\end{array}$

Appendix 2 Calculated composition of the starter and finisher diets 49

Appendix 3 Chemical and nutritional composition of the rapeseed extract used in the present experiment comparing with canola meal (Khajali and

Slominski, 2012) 


\section{Foreword}

Feed4Foodure is a public-private partnership between the Dutch Ministry of Economic Affairs, a consortium of various organizations within the animal production chain and the Animal Sciences Group of Wageningen UR. Feed4Foodure aims to contribute to sustainable and healthy livestock farming in the Netherlands, simultaneously strengthening our competitive position on the global market. The Feed4Foodure program line "Nutrition, Intestinal Health, and Immunity", aims to contribute to a reduction in the use of antibiotics in livestock farming by increasing general health and disease resistance. The main goals are to develop innovative measurement techniques, and the use thereof in innovative products and diet compositions.

The livestock sector faces challenges to sharply reduce antibiotic consumption. The program Nutrition - Intestinal Health - Immunity (VDI) strives to reduce antibiotic treatment in animals through nutritional interventions, which should defense against infectious diseases. The purpose of this experiment was to evaluate the effect of five different nutritional interventions of broilers after the neonatal period ( $d$ 14-28) on the performance, composition of the intestinal microbiota, intestinal morphology and gene expression in small intestinal tissue. In the present experiment, the effect of several dietary interventions provided during d $14-28$ of age on parameters related to immune competence of broiler chickens was examined. This experiment was performed within the framework of the Feed4Foodure program line "Nutrition, I ntestinal Health, and Immunity".

For the current study, scientist of Wageningen UR Livestock Research, Wageningen UR CVI and the Dutch GD Animal Health worked together with representatives from the various private partners, including Agrifirm, ForFarmers, Nutreco, De Heus, Cargill, DSM, Groep van Zes, DIVA, and Centrico. The authors thank the industry partners of the project team for their worthwhile input.

Dr. Mari Smits, leader Feed4Foodure program line "Nutrition, I ntestinal Health, and Immunity". 


\section{Summary}

The livestock sector faces challenges to sharply reduce antibiotic consumption. The program Nutrition - Intestinal Health - Immunity (VDI) strives to reduce antibiotic treatment in animals through nutritional interventions, which should improve immune competence. This experiment was conducted to investigate the effects of five nutritional interventions between 14 and 28 days of age on broiler performance ( $d 14-35$ ), and immune competence related parameters as composition of the intestinal microbiota ( $d 21$ and 28), and gene expression in gut tissue ( $d 21$ and 28). A total of 1,008 one-dayold male Ross 308 chicks was randomly distributed over 36 floor pens (28 birds per pen). Birds were allocated to one of the six (five dietary interventions besides a control treatment) iso-caloric ( $\mathrm{ME}_{\mathrm{N}} 13$ $\mathrm{MJ} / \mathrm{kg}$ ) experimental growing diets (d 15-28), with six replicate pens per treatment. Commercial starting and finishing diets were used from d1-d14 and d29-d35 of age, respectively. A high level $(25 \%)$ of rapeseed meal, containing glucosinolates as antinutritional factor, was included to the diets to provide a nutritional challenge. Five various nutritional interventions, differing in mechanism of action, including a plant extract (quercetin, $400 \mathrm{mg} / \mathrm{kg}$ ); an insoluble fiber (oat hulls, $50 \mathrm{~g} / \mathrm{kg}$ ); a prebiotic ( $\beta$-glucan, $100 \mathrm{mg} / \mathrm{kg}$ ); an anti-microbial protein (lysozyme, $40 \mathrm{mg} / \mathrm{kg}$ ) and $\omega-3$ fatty acids from fish oil $(40 \mathrm{~g} / \mathrm{kg}$ ) were applied in the growing phase (d 15-28). Dissection was done on 6 birds/pen on d21 and d28 of age. Feed intake of broilers fed the diet including oat hulls and lysozyme was reduced during the first week of the growing period (d14-21) compared to other groups. Birds adapted to consume diets including oat hulls and lysozyme after the first week of consumption, and feed intake was not affected by treatment after that (d22-28, d14-28 and d29-33). During the first week of the growing period, a trend of decreased BWG of broilers fed the diet including lysozyme (compared to the control $\mathrm{P}<0.05$ ), oat hulls and fish oil (compared to the control $\mathrm{P}>0.05$ ) was observed, but over the second week of the growing period (d22-28), broilers fed the diet including lysozyme showed increased BWG compared to the control and birds fed diets including quercetin and $\beta$-glucan $(P<0.05)$. Broilers fed the diets including fish oil and oat hulls also showed increased BWG during the second week of the growing period, but the differences with other groups were not significant. It seems that broilers fed diets including lysozyme, oat hulls and fish oil showed compensatory growth in the second week of the grower period. Considering the whole growing period, there was no significant difference in BWG between nutritional interventions. A trend of increased FCR in broilers fed the diets supplemented by lysozyme $(P<0.05)$ and oat hulls $(P>0.05)$ was observed during the first week of the growing period. Also an improved FCR in broilers fed the diets supplemented by lysozyme, oat hulls and fish oil was observed during the second week of growing period; nevertheless over the whole growing period, no significant effect of dietary treatment on FCR was observed. No carry-over effect of dietary treatment on BWG, feed intake and FCR was observed in the finishing period. Compared to the control diet, litter score improved by feeding oat hulls and fish oil (d28), and oat hulls and lysozyme (d33). On d21, hierarchical clustering of the group-averaged microbiota data showed no meaningful effect of dietary interventions based on the underlying taxonomic profiles. Alpha diversity by Shannon Index showed no differences between jejunum and ileum. Principal component analysis on microbiota showed that the oat hulls treatment was separated from data from the other experimental treatments, which were all centred around the origin, which is a general indication that the microbiota of the oat hulls fed birds differed from the other treatments. More specifically, a significant taxon-treatment association was found in the ileum within the genus Enterococcus, which was significantly higher in the oat hulls treatment compared to the control and fish oil fed birds, mainly at the expense of Lactobacilli. No effect of treatments on villus height of jejunum on $\mathrm{d} 21$ and of ileum ( $\mathrm{d} 21$ and 28) was observed. Villus height of lysozyme fed birds in jejunum at d28 was decreased compared to the control. No effect of treatments on crypt depth of jejunum on d21 and of ileum was observed. Jejunum crypt depth of the birds fed lysozyme in d28 was decreased compared to the control. In jejunum ( $d 21$ and 28), the total surface area of villi occupied by goblet cells $\left(\mu \mathrm{m}^{2}\right)$ and average total villi surface area $\left(\mu \mathrm{m}^{2}\right)$ were higher in chickens fed diet included oat hulls compared with other dietary interventions. Only marginal effects of dietary interventions on the expression of genes were observed. Compared to the control birds, genes related to growth-factor-activity (directly involved in wound healing processes) were expressed more in the birds fed the $\beta$-glucan included diet, while the genes related to anion-transmembrane-transporteractivity in the broilers fed the quercetin and oat hulls included diet were expressed less. In conclusion, dietary inclusion of oat hulls and lysozyme resulted in temporary reduction in performance. Dietary oat hulls inclusion slightly affected overall microbiota composition within and between jejunal and ileal digesta. 
Limited effects of nutritional interventions were observed on gene expression of the gut tissue, and the genes differently expressed between dietary treatments do not seem to be directly involved in immune related processes.

Despite the different types of interventions, parameters related to immune competence were only marginally affected by the tested products. It seemed that in this study inclusion of oat hulls, and probably $\beta$-glucans, had perspective to improve immune competence. It is recommended to revaluate some of the tested interventions, especially dietary inclusion of oat hulls and $\beta$-glucans, in broilers starting from day-old onward.

(c) 2015 Wageningen UR Livestock Research, P.O. Box 338, $6700 \mathrm{AH}$ Wageningen, The Netherlands, T +31 (0)317 4839 53, E info.livestockresearch@wur.nl, www.wageningenUR.nl/en/livestockresearch. Livestock Research is part of Wageningen UR (University \& Research centre). 


\section{Introduction}

\section{$1.1 \quad$ Immune competence and nutritional immunomodulation}

Immune competence is defined as the ability of the immune system to respond adequately on an antigenic stimulus by an appropriate immune response with a balance between tolerance and inflammation. Since the immune system is highly complex and tightly regulated, a profound understanding of how the avian immune system works is necessary to take full advantage of immune competence. The current state of knowledge of avian immunity lags behind that of many mammalian species. This topic may become more important to the poultry industry, given the current interest in using non-drug interventions to support the health and rapid and efficient growth in poultry. Appropriate nutrition becomes even more critical as anti-bacterials, anti-parasitics and other additives that promote animal health are eliminated due to consumer demands. Nutrition may aid in minimising the incidence of diseases by enhancing immune competence. It can be questioned, however, whether the diets in use today for realizing maximal production efficiency are sufficient for optimal immunity. Klasing (2007) distinguished six different mechanisms by which diet might affect immunity: 1) feeding the cells of the immune system, 2) feeding pathogens, 3) modifying the responses of leukocytes, 4) protecting against immunopathology, 5) influencing the microbial ecology of the gut, and 6) stimulating the immune system. In general, the immune system of the bird can be influenced by nutrition in ways of anatomical development of lymphoid tissues, mucus production, synthesis of immunologically active substances, cellular proliferation, cellular activation and movement, intracellular killing of pathogens, modulation and regulation of the immune process (Gershwin et al., 1985; Klasing, K. C. 1997). Nutritional immunomodulation represents a rational goal to allow efficient production of healthy birds. One of the major factors driving interest in the development of nutritional immuno-modulation is the removal of sub-therapeutic dietary antibiotics from poultry diets in many parts of the world, and consumer and legislative pressures to reduce or eliminate antibiotic growth promoters use elsewhere. The use of antibiotic growth promoters in poultry diets may influence immune function in at least reducing the interaction of Gl tract bacteria with the immune system of the bird suggesting that one of the mechanisms of action of it is to reduce the reliance of the bird on its own immune system to prevent clinical or subclinical disease (Korver, 2012). Consequently, reduced exposure of the bird to bacteria would reduce activation of the inflammatory response, and therefore the associated growth-suppressive effects. In an environment where growth-promoting antibiotics are not used, the bird would be more dependent upon its own immune system to avoid bacterial infections. The second manner is the environment under which many genetic selection programs for poultry take place. Commercial genetic selection under high sanitation may reduce the ability of poultry to respond to the diversity and intensity of field disease challenges. Thus, the need for a highly responsive inflammatory response may have been masked, and may have inadvertently been selected against.

\subsection{Specific feed ingredients and omics techniques}

The immuno modulatory effects of specific feed ingredients is assumed to be related to some functional components in these feed matrices. The mode of action of these components, however, is often unknown. Integration of "omics" techniques like transcriptomics, proteomics, and metabolomics, could fill in this knowledge gap. The data gained with these techniques would significantly contribute to the elucidation of the mechanisms how specific components and/or ingredients in feed positively influence functional processes in the Gl tract, and with this, the overall performance of farm animals. Combined information about gene-chemical associations retrieved from on-line available databases can be used to predict the in vivo biological activity of natural occurring chemical compounds, i.e. predict their "defined mode of action". Or contrariwise, this information can be used to identify compounds that have potential to influence the function of specific genes/proteins or biological processes. Such a data-mining approach has already accelerated the development of alternative or new dedicated supplements/additives for human foods. In vivo experiments are widely used to investigate the effects of nutritional interventions on immune related parameters in animals. In these studies animals are used as target animals, or as a model for humans. In vivo experiments, however, might increase the level of discomfort of the animals, are time and labour intensive, and costly. For some research questions, other types of experiments can be used as well, thereby lowering the level of disadvantages compared to in vivo experiments. 
Based on the available literature, it was hypothesized that nutritional interventions resulting in better protection against potential pathogens, including improving intestinal integrity, improving the functioning of the local immune system in the intestine, gut wall morphology and composition of microbiota, with the result that there is less need for the immune system to combat against antigens via severe inflammatory reactions. Table 1, based on a report by Van Krimpen et al. (2014), shows the effects of some dietary interventions during the post-neonatal phase on immune competence related parameters.

Table 1 Selection of nutritional interventions and their described effects (Van Krimpen et al., 2014) in the post-neonatal phase of monogastrics.

\begin{tabular}{|c|c|c|c|c|c|}
\hline \multirow[t]{2}{*}{ Intervention } & Gut & Local & Systemic & Microbiota & Performance \\
\hline & Integrity & i.s. & i.s. & & \\
\hline Glutamine & + & & + & & \\
\hline \multicolumn{6}{|l|}{ Plants and herbs } \\
\hline Chitosan & & & + & & \\
\hline Herb mixture & & + & + & & \\
\hline Quercetin & & & & + & + \\
\hline Black cumin & + & + & & & + \\
\hline Rice bran & & + & + & + & \\
\hline Alfalfa & & + & & + & \\
\hline \multicolumn{6}{|l|}{ Probiotics } \\
\hline Bacillus subtilis & + & & + & + & \\
\hline Lactobacillus bulgaricus & & + & + & & \\
\hline Prebiotics/ $\beta$ Glucans (neonatal) & + & + & & & \\
\hline \multicolumn{6}{|l|}{ Antimicrobial proteins } \\
\hline Antimicrobial peptide-A3/P5 ${ }^{1}$ & + & & & + & + \\
\hline Buforin $\mathrm{II}^{2}$ & + & & & + & + \\
\hline Lysozyme & + & + & + & & + \\
\hline Fish oil (maternal) & & + & & & \\
\hline
\end{tabular}

\subsection{Nutritional interventions}

In the present study, five different nutritional interventions, differing in mechanism of action, including a. a plant extract, quercetin (active substance of yellow onion), b. an insoluble fiber (oat hulls); c. a prebiotic ( $\beta$-Glucan), d. an antimicrobial protein (Lysozyme), and e. Omega-3 fatty acids from fish oil were applied.

Quercetin is a flavonoid compound that belongs to the class of flavonols. It can be found in most edible fruits such as apples, mostly in peels (Manach et al., 2004), in vegetables such as red onions and capers (Bhagwat et al., 2013), and is potentially beneficial for human and animal health. It has been found that dietary quercetin can be absorbed and metabolized by rats (Crespy et al., 2001; Chang et al., 2004; de Boer et al., 2005; Gee et al., 2004), pigs (Cermak et al., 2003; de Boer et al., 2005), humans (Hong and Mitchell, 2004; Manach et al., 2004; Mullen et al., 2004; Spencer et al., 2003; Wang and Morris, 2005) and broilers (Rupasinghe et al, 2010). Rupasinghe et al. (2010) administered quercetin to a broiler diet as a pure substance and detected quercetin metabolites in the plasma and several tissues (liver, thigh, and breast muscle and duodenum). Many in vitro biological properties of quercetin and its glycosides, such as modulation of cell signalling pathways (Soundararajan et al., 2008), reduction of oxidative DNA damage (Wilms et al., 2005), lipid oxidation in rodents (Molina et al., 2003), and in vitro antioxidant activity (Arts et al., 2004) have been demonstrated. Studies in mice (Comalada et al., 2006; Hamalainen et al., 2007; Huang et al., 2010; Orsolić et al., 2004; Rotelli et al., 2003) and human (Boots et al., 2011; Sternberg et al., 2008) showed that quercetin has anti-inflammatory as well as anti-bacterial properties (Waage and Hedin, 1985).

Many feed ingredients, such as barley, oats, and soybean meal contain a considerable amount of insoluble fibre (Bach Knudsen, 1997). Dietary fibre has been considered to be a diluent in poultry diets, with negative effects on voluntary energy intake and nutrient digestibility. However, many 
studies indicated that moderate amounts of fibre improve gizzard function (Hetland and Svihus, 2001; Rogel et al., 1987; Svihus, 2011), digestibility of non-fibre nutrients (Amerah et al., 2007; Amerah et al., 2009; Gonzalez-Alvarado et al., 2010; Jimenez-Moreno et al., 2009b; Mateos et al., 2012), gastrointestinal tract (GIT) health (Kalmendal et al., 2011; Mateos et al., 2012), and growth performance (Gonzalez-Alvarado et al., 2007; Jimenez-Moreno et al., 2013a) in broilers. Although it was expected that the beneficial effect of fiber is due to a slower digesta passage speed, better action of enzymes and / or killing microbes by $\mathrm{pH}$ reduction is also the case.

Prebiotics are antibiotic growth promotors (AGPs) alternatives having three criteria; non-digestible by host enzymes, fermentable in the gastrointestinal tract and selectivity in stimulation of intestinal microbiota and metabolic activity (Gibson et al., 2004; Van Loo, 2004). Therefore, they improve the intestinal ecosystem, intestinal tissue, immunity and general host status (Gibson et al., 2004). Prebiotics could alter the intestinal ecosystem via promoting competitive exclusion of pathogenic microbes and selective colonization by beneficial microbes, leading to improvement of poultry performance (Biggs et al., 2007). Mannan-oligosaccharides (MOS) are mannose-rich carbohydrates, derived from yeast cell walls (Sentandreu and Northcote, 1968, 1969; Young et al., 1998), and can inhibit the growth of harmful bacteria and stimulate the non-specific immune system; activates the healthiness and growth performance of birds (Ferket, 2004), reduces serum cholesterol with no effect on the triglycerides (Yalçinkaya et al., 2008). Currently, MOS products, particularly those derived from the cell wall of Saccharomyces cerevisiae, are extensively used as natural feed additives in livestock and poultry because of documented benefits in performance (Hooge, 2004; Rozeboom et al., 2005; Rosen, 2007) and gastrointestinal health (Spring et al., 2000; Sims et al., 2004; Baurhoo et al., 2007b; Yang et al., 2008; Baurhoo et al., 2009). Galacto-oligosaccharides is structurally similar to cell surface glycoconjugates that are used by pathogens for adherence in the gut and, in this way, protect against the colonization and growth of pathogens (Newburg, 2000; Searle et al., 2010; Shoaf et al., 2006). Prebiotics bind to dectin-1-Like receptor heterophils and monocytes, and as a result, heterophils are stimulated to increase production of cytokines. Studies have demonstrated that dietary immuno-modulators such as $\beta$-glucans show beneficial results in a wide variety of animal species (Chae et al., 2006; Guo et al., 2003). The immuno-stimulant and immuno-modulatory effects of $\beta$ glucan polysaccharides result in the regeneration of the host's ability to resist life-threatening opportunistic infections (Rieder et al., 2013). The immuno-modulatory process initiates when the $\beta$ glucan binds to cell surface receptors of macrophages, lymphocytes and neutrophils (Chen and Seviour, 2007; Guo et al., 2003). $\beta$-glucan activates B-lymphocytes and macrophages through dectin1, CR3, lactosylceramide, scavenger receptors and Toll-like receptors (Le et al., 2011; Taylor et al., 2002), modulating the immune system and inducing the production of cytokines (Cheng et al., 2004). In the present experiment, a pure $\beta$ - 1,3 glucan was added to diet that was produced by the unicellular Euglena gracilis. The product is widely used as a pure $\beta$-glucan in research on immune competence. The action of antimicrobial proteins is based on a direct inhibitory effect on proliferation of Clostridium perfringens and to the production of alpha-toxin.

Lysozyme (muramidase), one of the best known and best described animal proteins (Callewaert and Michiels, 2010), forms around 3.5\% of total egg white protein (Burley and Vadehra, 1989) and has bactericidal properties (Fleming, 1922; Salton, 1957) due to its ability to hydrolyse $\beta$-linkages between $\mathrm{N}$-acetylmuramic acid and $\mathrm{N}$-acetyl glucosamine in the peptidoglycan cell walls of certain Gram-positive bacteria (Ohno and Morrison, 1989; Phillips, 1966). Following chemical and/or thermal modification, however, it has also been found to be bacteriostatic toward Gram-negative bacteria (Ibrahim et al., 1994; J ohnson, 1994; Masschalck et al., 2001). One of the main roles of lysozyme is most probably to prevent invasion and proliferation of bacteria inside the egg during the preincubation and incubation periods (Board and Fuller, 1974; Wellman-Labadie et al., 2008b; D'Alba et al., 2010). Following the addition of substances like EDTA, butyplaraben or tripolyphosphate, the activity of lysozyme was enhanced enough to control growth of the Gram-negative Escherichia coli (E. coli) (Durance, 1994; Boland et al., 2003). In addition to its antimicrobial function, lysozyme has been shown to play an essential role as a general defence molecule in the innate immune system of many vertebrates due to its continuous presence in various body fluids, including mucus, ejaculate, and blood (Millet et al., 2007; Rowe et al., 2013). In most vertebrates, including birds, both plasma lysozyme concentration and activity has been observed to increase along with pathogen exposure or inflammation processes (Caruso et al., 2002; Maraghi et al., 2012; Millet et al., 2007) and is accompanied by an increased blood leukocyte profile (Figuerola et al., 1999; Maxwell and Robertson, 1998). Plasma lysozyme is not only lethal to lysozyme-susceptible pathogens but may also be involved in non-specific immune processes such as opsonisation, leading to phagocytosis of Gram-negative 
bacterial invaders that are less responsive to lysozyme (Abergel et al., 2007; Callewaert et al., 2008). Evidence exists for both synergistic (Bugla-Ploskonska et al., 2008; Futoma-Koloch and BuglaPloskonska, 2009) interactions between lysozyme and plasma or serum complement activity. Complement represents just one of a number of bactericidal cascade mechanisms consisting of more than 30 individual plasma proteins that participate in pro-inflammatory, chemotactic and opsonic activities, thereby forming the intersection between non-specific humoral and cellular immune functions in vertebrates (Holland and Lambris, 2002).

Fish oil, derived from the tissues of oily fish, is a commonly and economic fishery sub-product, and can partially replace soybean oil in broiler diets. It contains $n-3$ polyunsaturated fatty ( $n-3$ or omega- 3 PUFA), such as eicosapentaenoic acid EPA (20:5 n-3) and docosahexaenoic acid (DHA, 22:6 n-3) (Hulan et al., 1988). The n-6 PUFA arachidonic acid (ARA) is the precursor of prostaglandins, leukotrienes and related molecules, which have important roles in inflammation and regulation of immunity (Calder, 2006). Dietary supplementation with fish oil resulted in reduction of ARA in cell membranes, which was replaced with EPA, leading to decreased production of ARA-derived proinflammatory mediators (Calder, 2006; Cherian, 2011; Fritsche et al., 1991; He et al., 2007; Kelley and Daudu, 1993; Korver and Klasing, 1997; Liu et al., 2014; Parmentier et al., 1997; Yang et al., 2008). In addition, it has been shown that EPA and DHA supplements in poultry diets are incorporated into egg yolks and are available to the developing embryo in the liver and residual yolk (Koppenol et al., 2014). The offspring of breeding chickens fed a diet supplemented with n-3 PUFAs showed changes in antibody and cell-mediated immune responses (Sijben et al., 2001; Wang et al., 2000, 2002). I mbalanced eicosanoid production can affect poultry health, promoting cardiac problems and sudden death (Ajuyah et al., 2003; Bautista-Ortega et al., 2009; Saki and Hemati Matin, 2011; Squires and Summers, 1993;). The n-3 PUFA also can be improved in poultry meat (Hulan et al., 1989) and characteristics of processed products (Yang et al., 2010). Fish oil should replace soybean oil in diets only at low levels in order to minimize its latent negative impact on the sensory attributes of meat broiler (Bou et al., 2004; Lopez-Ferrer et al., 2001). However, the sensory alterations were not evident at 2-4\% (Jeun-Horng et al., 2002) fish oil supplementation in broiler diets. Based on their described impacts on health status of animals, it is hypothesized that dietary supplementation of quercetin, oat hulls, B-glucans, lysozyme or omega-3 PUFA affects immune competence of broilers.

This study aims, to evaluate the nutritional interventions that directly or indirectly (via the microbiota) engage the optimal development of the immune competence of broilers in the post-neonatal phase (after day 14 of age). Therefore, the effects of the 5 dietary interventions in the grower diets applied after the neonatal phase (d14-28) on growth performance of broilers, the composition of the microbiota (16S rRNA sequencing), and functional and immune status of small intestinal tissue by determining genome-wide gene expression profiles and gut morphology were determined. 


\section{$2 \quad$ Material and methods}

The experimental protocol conformed to the standards for animal experiments and was approved by the Ethical Committee of Wageningen UR, the Netherlands (project nr. 44-00321/approval nr. 201309.b). Animal care guidelines were used as provided by the Euro guide recommendations for animal use for experimental and other scientific purposes (Forbes et al., 2007).

\subsection{Start date and end date of the experiment}

The experiment was performed from $26^{\text {th }}$ of June (day 0) to $31^{\text {th }}$ of July 2014 (day 35). Day-old chicks were purchased from the hatchery Van Hulst, Veldhoven. At the end of the experiment, the chickens were delivered to butchery Kapteijns, Diessen. The trial was performed using 1,080 day-old Ross 308 broiler cockerels.

\subsection{Experimental facility and housing}

The experiment was conducted at the practical research farm of feed producer De Heus (Eerde, The Netherlands).

Table 2 Experimental design in summary.

\begin{tabular}{ll} 
Item & Number \\
Treatments & 6 \\
\hline Replicates (pens) per treatment & 6 \\
\hline Total number of pens & 36 \\
\hline Broilers per pen & 28 \\
\hline Broilers per treatment & 168 \\
\hline Total number of broilers & 1,080 (1008 used for the study; 72 reserve birds) \\
\hline
\end{tabular}

\subsubsection{Experimental animals}

A total of 1,080 one-day-old male Ross 308 chicks were used and randomly allocated to six experimental treatments (Table 2 ). After arrival, the chicks were randomly picked from the chick boxes and distributed among the 36 pens: the first chick in pen 1, the second chick in pen 2, and so on until there are 28 chicks in each pen ( 36 pens with 28 chicks / pen) in a mechanically ventilated room provided with facilities to control temperature, ventilation and lighting. The chicks were then weighed as a group per pen. The distribution of treatments over the 36 pens was determined by drawing lots. The surface area of the pens was $1.5 \mathrm{~m}^{2}$. Each pen contained a feeding trough and three drink cups belonging to a water line. Wood shavings were used as bedding material. The broiler unit was continuously illuminated during the first two days. The broilers were sexed at the hatchery. The birds were supplied by a commercial hatchery (Van Hulst, Veldhoven, The Netherlands). Chicks passed the adaptation period (0-14 days), followed by the experimental periods 14-21 days, 21-28 days, and the finishing period (28-35 days). During the first 14 days, all the animals received the same standard starter feed, where after the experimental diets were provided from 14-28 days. From day 29 onwards, a standard finisher diet was provided to all remaining birds. On day 21 and 28, randomly 6 chicks per pen were sacrificed for further analysis. The remaining 16 chicks per pen (depending on the base) were on day 35 discharged to a regular butcher. The experimental feeds were optimized by De Heus and produced by Research Diet Services in Wijk bij Duurstede (The Netherlands). All feeds were pelleted (3.2 mm diameter). After pelleting, starter feed was crumbled. Grower and finisher feeds were provided as whole pellet. The feed was delivered as bagged. Feed and water was unlimited provided to the animals.

\subsubsection{Climate}

Realized relative humidity and stable temperature was maintained by means of a climate computer. Temperature inside the room was increased to $36^{\circ} \mathrm{C}$ one day before arrival of the chicks. From $\mathrm{d} 1$, the 
temperature was gradually decreased to $20^{\circ} \mathrm{C}$ according to Table 3. Relative humidity was gradually increased from $60(\mathrm{~d} 0)$ to $75 \%(\mathrm{~d} 33)$ during the experiment.

Table 3 Temperature schedule.

\begin{tabular}{ll} 
Age $(\mathrm{d})$ & Temperature $\left({ }^{\circ} \mathrm{C}\right)$ \\
\hline 1 & 35 \\
\hline 7 & 31 \\
\hline 14 & 28 \\
\hline 21 & 27 \\
\hline 35 & 25 \\
\hline
\end{tabular}

\subsubsection{Light}

On day 0 and 1, the animals were given continuous light (24L: 0D) with a light intensity of 20 lux. From day 2 onwards, a day-night light schedule of 18 hours light and 6 hours of darkness (18L: 6D) was used. The light intensity was set at 20 lux during the entire experimental period.

\subsubsection{Health and Failure}

All fallen animals were noted and weighed, whereas the failure cause was determined by section. The fallen animals were kept refrigerated and offered for daily section. During the test the animals were checked daily on abnormalities by the animal technicians. Animals with a deviation were removed from the trial after consultation with the researchers. At the time of removal, the animal weight was noted.

\subsubsection{Vaccination}

The chicks were vaccinated immediately after arrival at IB + NCD (vaccination coarse spray droplet).

\subsection{Experimental measurements}

\subsubsection{Diets}

Four iso-caloric and iso-nitrogenous experimental grower diets ( $\mathrm{ME}=11.8 \mathrm{MJ} / \mathrm{Kg}$ and crude protein= $195 \mathrm{~g} / \mathrm{kg}$ ) were formulated. Per $\mathrm{kg}$ of diet, $40 \mathrm{mg}$ of Lysozyme (from chicken egg white, protein $\geq 90 \%$, CAS Number 12650-88-3, Sigma-Aldrich, Zwijndrecht, The Netherlands), 100 mg $\beta$-glucans ( $\beta$-1,3-Glucan from Euglena gracillis CAS Number 9051-97-2, Sigma-Aldrich, Zwijndrecht, The Netherlands) and 400 mg quercetin (purity $>95 \%$, CAS Number 117-39-5, Sigma-Aldrich, Zwijndrecht, The Netherlands) were supplemented on top of the control diet, while $40 \mathrm{~g} / \mathrm{kg}$ fish oil was included in the control diet at the expense of animal fat. Oat hulls $(50 \mathrm{~g} / \mathrm{kg}$ ) were inserted to the control diet at the expense of maize with increasing levels of soybean meal and soya oil (10 to 12.2 for soybean meal and 2 to 4.88 for soya oil). So the highest amount of crude fat was analysed in the oat hulls-included diet (12.6 vs $9.9 \%$ in other experimental diets). The composition of the grower diets is shown in appendix 1 . The composition of the starter and finisher diets is shown in appendix 2 . In the present experiment, rapeseed meal was added to nutritional interventions $(25 \%)$ to cause a nutritional challenge. Compared to soybean meal, rapeseed meal contains relatively high amounts of non-starch polysaccharides, glucosinolates, sinapines, tannins, erucic acid and phytate, that might have antinutritional capacities and hamper among others absorption of nutrients by the gut cell wall. The chemical and nutritional composition of the used rapeseed extract comparing with canola meal (Khajali and Slominski, 2012) is presented in appendix 3. Diets were in duplo analysed for dry matter (International Organization for Standardization, 1998), crude protein (International Organization for Standardization, 1997), crude fat (International Organization for Standardization, 1999), crude fibre (International Organization for Standardization, 1988), ash (International Organization for Standardization, 2002), Starch content was analysed enzymatically as described by Brunt (1993). Sugars were extracted from the feed samples, using $40 \%$ ethanol, and determined as described by Suárez et al. (2006). Analysis of NDF was based on a modified method of Van Soest (1973), as described by Suárez et al. (2006). 


\subsubsection{Performance}

Body weight of birds was determined per pen at $0,14,21,28$ and 33 days of age. Feed intake per pen was determined at 14, 21, 28 and 33 days of age (provided feed minus remaining feed at 14, 21, 28 and 33 days of age). Body weight (BW) gain and feed conversion ratio (FCR) of broilers in each pen was calculated at the end of each feeding period (at 14, 21, 28 and 33 days of age). Also BW gain and FCR for the entire growth period was calculated. Culling, mortality and general health were recorded daily (including probable causes of any culling, illness or deaths). D0 to d14 was defined as the starter period, d15 to d21 as the grower- 1 period, d22 to d28 as the grower- 2 period, and d29- d33 as the finisher period.

\subsubsection{Litter quality}

Litter quality was visually scored on a 0 to 10 point scale on 28 and 33 days of age by one person. The scores and the description of each score are presented in Table 4.

Table $4 \quad$ Litter quality scores.

\begin{tabular}{ll} 
Score & Description \\
\hline $\mathbf{1 0}$ & Dry and friable litter \\
\hline $\mathbf{9}$ & Dry and $10 \%$ caked litter \\
\hline $\mathbf{7}$ & Almost dry and $20 \%$ caked litter \\
\hline $\mathbf{6}$ & Almost dry and $30 \%$ caked litter \\
\hline $\mathbf{5}$ & Almost dry and $40 \%$ caked litter \\
\hline $\mathbf{4}$ & Moist and $50 \%$ caked litter \\
\hline $\mathbf{3}$ & Moist and $60 \%$ caked litter \\
\hline $\mathbf{1}$ & Moist and $70 \%$ caked litter \\
\hline $\mathbf{0}$ & Wet and $80 \%$ caked litter \\
\hline
\end{tabular}

\subsubsection{Dissection and sample collection}

At 21, and 28 days of age, 6 birds per pen were euthanized by electrocution. Subsequently, the chest cavity and the abdomen were opened and the small intestine was ligated and removed from the bird. The digesta of the middle part of the jejunum, defined as the $10 \mathrm{~cm}$ before and after the middle of the jejunum, was collected from all birds. The digesta was collected by gently stripping the gut segment into a plastic container. The digesta of all animals per pen were pooled and immediately after collection frozen on dry ice and stored at $-80^{\circ} \mathrm{C}$ until further analysis on microbiota composition. The digesta was collected in the order of pen numbering. Digesta samples were ground $(0.5 \mathrm{~mm})$ by $\mathrm{CVI}$ (The Netherlands).

From all birds three samples ( $2 \mathrm{~cm}$ per sample) of intestinal tissue of the jejunum were collected. One sample was put in a formalin filled tube and stored at $-80^{\circ} \mathrm{C}$ until further analysis on intestinal morphology (villus height and crypt depth), and number and size of goblet cells. Sample two was directly placed into liquid nitrogen and stored at $-80^{\circ} \mathrm{C}$ until further analysis on genome-wide gene expression profiling in jejunal tissue. Sample 3 was taken as reserve sample and also directly placed in liquid nitrogen, followed by storage at $-80^{\circ} \mathrm{C}$ for future unforeseen analysis. Villus height, crypt depth $(\mu \mathrm{m})$ and goblet cells were determined by GD Animal Health (Deventer, The Netherlands) per individual bird, whereas microbiota composition and genome-wide gene expression profiling were determined in pooled samples of birds per pen by CVI (The Netherlands).

\subsubsection{Microbiota}

Microbiota diversity index and microbiota composition of the jejunal and ileal digesta were measured in a pooled sample of digesta of six birds (content of $2 \mathrm{~cm}$ jejunum length per sample) per pen on days 21 . Samples of day 28 were collected but not analysed, because it was hypothesised that). To isolate DNA samples of $\mathrm{d} 21$ were mixed in a $1: 1$ ratio with phosphate buffered saline (PBS) and centrifuged for $5 \mathrm{~min}$ at $4^{\circ} \mathrm{C}$ at $300 \times \mathrm{x}$. Supernatant was collected and centrifuged for $10 \mathrm{~m}$ at $4^{\circ} \mathrm{C}$ at 9,000xg. DNA was extracted from the most sensitivepellet using the "QIAamp DNA stool minikit" according to the dietary interventions. manufacturers' instructions. Quality and quantity of DNA was 
checked using the NANOdrop (Agilent Technologies). PCR was used to amplify the 16S rDNA V3 fragment using forward primer V3_F (CCTACGGGAGGCAGCAG) and reverse primer V3_R

(ATTACCGCGGCTGCTGG). PCR conditions were as follows: $2 \mathrm{~m}$ at $98^{\circ} \mathrm{C}, 15 \times\left(10 \mathrm{~s}\right.$ at $98^{\circ} \mathrm{C}, 30 \mathrm{~s}$ at $55^{\circ} \mathrm{C}, 10 \mathrm{~s}$ at $\left.72^{\circ} \mathrm{C}\right), 7 \mathrm{~min}$ at $72^{\circ} \mathrm{C}$. PCR efficiency was checked on agarose gel by visual inspection. Samples of jejunum were sequenced by targeted-amplicon $16 \mathrm{~S}$ sequencing and analysed for taxonomy profile per sample, alpha diversity and beta diversity. This included possible taxonomy association with treatments. Pseudo reads were clustered into OTUs per sample at $97 \%$ similarity and OTU-representative sequences were aligned against the aligned Greengenes core set (13_8 release). Chimeras were removed with Chimeraslayer. Standard alpha diversity metrics ("Chao1", "observed species", "PD whole tree", "Shannon" ,based on the species level data) were calculated for the $97 \%$ similarity clustering with 94,038 sequences/sample.

\subsubsection{Genome-wide gene expression profiling}

RNA Extraction Tissue

Total RNA was extracted from 50 to $100 \mathrm{mg}$ jejunum and ileal tissue. All samples were homogenised using the TisuPrep Homogenizer Omni TP TH220P) in TRizol reagent (Life Technologies) as recommended by the manufacturer with minor modifications. The homogenised tissue samples were dissolved in $5 \mathrm{ml}$ of TRizol reagent. After centrifugation the supernatant was transferred to a fresh tube. Subsequently, Direct-zol ${ }^{\mathrm{TM}}$ RNA MiniPrep Kit by Zymo Research was used as described by the manufacturer. The RNA was quantified by absorbance measurements at $260 \mathrm{~nm}$. Quality Control was performed by Agilent Bioanalyser.

Labelling, Hybridization, Scanning and Feature Extraction

Labelling of RNA was done as recommended by Agilent Technologies, using the One-Color Microarray-

Based Gene Expression Analysis Low input Quick Amp Labelling. The input was 10 ng of total RNA, and $600 \mathrm{ng}$ of labelled cRNA was used on the eight pack array.

Hybridization was performed as described in the One-Color Microarray-Based Gene Expression Analysis Low input Quick Amp Labelling protocol from Agilent in the hybridization oven (G2545A hybridization Oven Agilent Technologies). The hybridization temperature was $65^{\circ} \mathrm{C}$ with rotation speed $10 \mathrm{rpm}$ for 17 hours. After 17 hours the arrays were washed as described in the One-Color MicroarrayBased Gene Expression Analysis Low input Quick Amp Labelling protocol from Agilent.

The arrays where scanned using the DNA microarray scanner with Sure scan high resolution Technology from Agilent Technologies. Agilent Scan Control with resolution of $5 \mu \mathrm{m}, 16$ bits and PMT of $100 \%$. Feature extraction was performed using protocol 10.7.3.1 (v10.7) for one colour gene expression.

\section{Data analysis}

The data were analysed by using R (v3.0.2) by executing different packages, including LIMMA and arrayQualityMetrics. The data were read in and background corrected (method="normexp" and offset=1) with functions from the R package LIMMA (Gentleman et al., 2005) from Bioconductor (Gentleman et al., 2004). Quantile normalisation of the data was done between arrays. The duplicate probes mapping to the same gene were averaged (by using the avereps function in R/Bioconductor) and subsequently the lower percentile of probes were removed in a three-step procedure, 1 ) get the highest of the dark spots to get a base value, 2) multiply by 1.1 and 3) the gene/probe must be expressed in each of the samples in the experimental condition.

To determine the effect of the experimental treatments on gene expression in intestinal tissue at each time point, six specific contrasts were defined within the R package LIMMA.

Functional association data mining

A Gene Set Enrichment Analysis (GSEA) was performed on all different contrasts compared to the respective control (Mootha et al., 2003, Subramanian et al., 2005). Default settings were used with the exception for the permutations which were performed on the gene set. Four gene set databases (v3.0) were loaded for analysis. Three Gene Ontology related gene sets ('biological processes', 'molecular function', and 'cellular component' and one pathway related database 'Kyoto Encyclopedia of Genes and Genomes (KEGG)' were used for all analyses. Furthermore, all annotated probes (i.e. genes) were used as input, after transforming them to human gene names. 
Relative bursa and spleen weight

At 21 and 28 days of age bursa and spleen were dissected from six birds per pen for bursa and spleen weight determination. Bursa and spleen weights were expressed relative to the individual BW of the birds.

\section{$2.4 \quad$ Statistical analysis}

The experimental data (performance, litter quality, bursa/spleen content, and gut morphology data) were analysed using Genstat statistical software (Genstat 8 Committee, 2002). Statistical significance is declared at $\mathrm{P}<0.05$, with $0.05<\mathrm{P}<0.10$ considered as a near-significant trend. The $\mathrm{P}$-value of the treatment effect and the LSD (least significant difference $(P=0.05)$ ) were provided per response parameter.

Response parameters were analysed using ANOVA (analyses of variance) according the following model:

$Y_{i j}=\mu+$ Treatment $_{i}+$ Error $_{i j}$

Where:

Y Response parameter

$\mu \quad$ General mean

Treatment Effect of diet $(i=1 \ldots 6)$

Error $\quad$ Error term

If an overall statistical treatment effect was found ( $P$ value $<0.05$ ), a Fisher protected t-test was used for analysing pair-wise differences. Pairwise differences are marked with a letter in superscript. In running Shannon diversity index, for the comparisons, not one taxon came through the filter, a was $<0.05$ and relative-abundance limit was 0.005 . 


\section{Results}

\subsection{General}

No adverse events occurred during the course of the experiment. Average performance parameters of all broilers during the experiment are presented in Table 5. The average weight of the broilers at arrival was $40 \mathrm{gram}$. During the period that the experimental diets were provided, the performance level of the broilers in the present study was below the Ross 308 performance standards of male broilers (Ross, 2014), as shown by lower body weights at d21 and d28. Body weight at d33, however, met the Ross standard, indicating compensatory growth after the switch to commercial finisher diet. From d14 onwards (start of providing the experimental diets) mortality amounted 1.2\%

Table 5 Performance data of male broilers during the experiment between 0 and 33 days of age.

\begin{tabular}{|c|c|c|}
\hline Performance data & Experiment & $\begin{array}{l}\text { Ross } 308 \text { standard } \\
\text { performance data }\end{array}$ \\
\hline Body weight day 0 (g) & 40 & 42 \\
\hline Body weight day 14 (g) & 485 & 488 \\
\hline Body weight day 21 (g) & 912 & 959 \\
\hline Body weight day $28(\mathrm{~g})$ & 1393 & 1576 \\
\hline Body weight day $33(\mathrm{~g})$ & 2088 & 2075 \\
\hline Body weight gain day $28-33$ (g/d) & 139 & 100 \\
\hline Body weight gain day $0-33(\mathrm{~g} / \mathrm{d})$ & 60.2 & 59.8 \\
\hline Feed intake day $0-33(\mathrm{~g} / \mathrm{d})$ & 91.1 & 89.6 \\
\hline Feed conversion ratio day $0-33(\mathrm{~kg} / \mathrm{kg})^{1}$ & 1.519 & 1.499 \\
\hline
\end{tabular}

\subsection{Diets}

The results of the chemical analysis of the different diets are presented in Table 6, and the dietary ingredients and calculated nutrient concentrations of the experimental diets (grower diets) are presented in Appendix 1. Calculated composition of the starter and the finisher diets is presented in Appendix 2. Analysed crude protein, crude fat, crude fibre, starch and sugars contents were in agreement with the calculated concentrations.

Table 6 Chemical analysis of the grower diets $(\mathrm{g} / \mathrm{kg})$.

\begin{tabular}{|c|c|c|c|c|c|c|}
\hline Days & Control & Quercetin & Oat hulls & Lysozyme & $\beta$-glucan & Fish oil \\
\hline $\begin{array}{l}\text { Crude } \\
\text { protein }\end{array}$ & 198 & 196 & 201 & 200 & 196 & 199 \\
\hline Crude fat & 105 & 105 & 130 & 104 & 104 & 104 \\
\hline Starch & 340 & 343 & 277 & 341 & 340 & 343 \\
\hline Sugars & 45 & 46 & 42 & 46 & 46 & 46 \\
\hline
\end{tabular}

\subsection{Performance}

The results of feed intake $(\mathrm{g} / \mathrm{d})$ of broilers per treatment for the growing (d14-28) and finishing periods (d29-33) are presented in Table 7. Feed intake of broilers fed the diet including oat hulls and lysozyme was reduced during the first week of growing period (d14-21) compared to other groups, but feed intake was not affected by treatment after that (d22-28, d14-28 and d29-33). Birds adapted to consume diets including oat hulls and lysozyme after the first week of consumption. 
Table 7 Feed intake $(\mathrm{g} / \mathrm{d})$ presented per treatment for the different experimental periods (d1433).

\begin{tabular}{|c|c|c|c|c|c|c|c|c|}
\hline Days & Control & Quercetin & $\begin{array}{l}\text { Oat } \\
\text { hulls }\end{array}$ & Lysozyme & $\begin{array}{l}\boldsymbol{\beta}- \\
\text { glucan }\end{array}$ & Fish oil & P-value & SE \\
\hline $14-21$ & $117 a$ & $117 a$ & $112 b$ & $107 c$ & $117 a$ & $117 a$ & $<0.001$ & 2.3 \\
\hline $22-28$ & 167 & 178 & 177 & 185 & 171 & 177 & 0.135 & 6.6 \\
\hline $14-28$ & 142 & 147 & 145 & 146 & 144 & 147 & 0.494 & 3.1 \\
\hline $29-33$ & 235 & 235 & 235 & 237 & 234 & 235 & 0.995 & 5.5 \\
\hline 14-33 & 176 & 182 & 181 & 184 & 177 & 181 & 0.436 & 4.5 \\
\hline
\end{tabular}

The results of body weight gain (BWG, g/d) of broilers per treatment for the growing (d14-28) and finishing periods (d29-33) are presented in Table 8. During the first week of the growing period (d1421), BWG of broilers fed the diet including lysozyme decreased compared to control $(P<0.05)$, where a trend of decreased BWG was observed for the oat hulls and fish oil fed birds, compared to control $(P>0.05)$ was observed. Birds adapted to the consumption of oat hull, fish oil and lysozyme diets in the first week. Over the second week of the growing period (d22-28), broilers fed the diet including lysozyme showed increased BWG compared to the control and birds fed the diets including quercetin and $\beta$-glucan $(P<0.05)$. Broilers fed the diets including fish oil and oat hulls also showed numerically increased BWG during the second week of grower period (d22-28) but the differences with other groups were not significant. It seems that during the second week of the growing period (d22-28), broilers fed diets including lysozyme, oat hulls and fish oil tried to have compensatory growth. There was no significant difference in BWG between nutritional interventions considering the whole growing period.

Table 8 Body weight gain $(\mathrm{g} / \mathrm{d})$ presented per treatment for the different experimental periods (d14-33).

\begin{tabular}{|c|c|c|c|c|c|c|c|c|}
\hline Days & Control & Quercetin & $\begin{array}{l}\text { Oat } \\
\text { hulls }\end{array}$ & Lysozyme & $\begin{array}{l}\beta- \\
\text { glucan }\end{array}$ & Fish oil & P-value & SE \\
\hline 14-21 & $64^{\mathrm{ab}}$ & $65^{a}$ & $60^{b}$ & $55^{c}$ & $62^{a b}$ & $61^{b}$ & 0.002 & 2.4 \\
\hline $22-28$ & $62^{b}$ & $65^{b}$ & $74^{\mathrm{ab}}$ & $77^{a}$ & $63^{b}$ & $70^{\mathrm{ab}}$ & 0.004 & 4.1 \\
\hline $14-28$ & 63 & 65 & 67 & 66 & 63 & 66 & 0.109 & 1.6 \\
\hline $29-33$ & 138 & 141 & 137 & 140 & 141 & 137 & 0.818 & 4.0 \\
\hline $14-33$ & 83 & 85 & 85 & 85 & 83 & 85 & 0.666 & 1.8 \\
\hline
\end{tabular}

The results of feed conversion ratio (FCR) of broilers per treatment for the growing (d14-28) and finishing periods (d29-33) are presented in Table 9. Compared to the control treatment, increased FCR in broilers fed the diets supplemented by lysozyme $(P<0.05)$, and a trend to increased FCR in oat hulls $(P>0.05)$, was seen during the first week of growing period (d14-21). I mproved FCR in broilers fed the diets supplemented with lysozyme, oat hulls and fish oil compared to control was seen during the second week of the growing period (d22-28); nevertheless, over the whole growing period no significant effect of dieatry tratment on FCR was seen. No carry-over effect of dietary treatment on BWG, feed intake and FCR was seen in the finishing period.

Table 9 Feed conversion ratio (FCR) presented per treatment for the different experimental periods (d14-33).

\begin{tabular}{ccccccccccc} 
Days & Control & Quercetin & $\begin{array}{c}\text { Oat } \\
\text { hulls }\end{array}$ & Lysozyme & B- & Fish oil & P-value \\
14-21 & $1.42^{\mathrm{b}}$ & $1.42^{\mathrm{b}}$ & $1.48^{\mathrm{ab}}$ & $1.54^{\mathrm{a}}$ & $1.45^{\mathrm{b}}$ & $1.45^{\mathrm{b}}$ & 0.014 & 0.034 \\
\hline $\mathbf{2 2 - 2 8}$ & $1.94^{\mathrm{a}}$ & $1.87^{\mathrm{ab}}$ & $1.70^{\mathrm{c}}$ & $1.69^{\mathrm{c}}$ & $1.88^{\mathrm{ab}}$ & $1.77^{\mathrm{c}}$ & 0.001 & 0.049 \\
\hline $\mathbf{1 4 - 2 8}$ & 1.64 & 1.62 & 1.59 & 1.64 & 1.64 & 1.60 & 0.200 & 0.025 \\
\hline $\mathbf{2 9 - 3 3}$ & 1.70 & 1.67 & 1.71 & 1.70 & 1.67 & 1.71 & 0.716 & 0.036 \\
\hline $\mathbf{1 4 - 3 3}$ & 1.66 & 1.64 & 1.63 & 1.64 & 1.65 & 1.63 & 0.601 & 0.021 \\
\hline
\end{tabular}




\subsection{Litter quality}

The results of litter condition score per treatment for two different samplings ( $d 28$ and d33) are presented in Table 10.

Table 10 Litter condition scorel presented per treatment for two different samplings ( $d 28$ and d33).

\begin{tabular}{lcccccccc} 
Days & Control & Quercetin & Oat hulls & Lysozyme & $\beta$-glucan & Fish oil & P-value & SE \\
\hline $\mathbf{2 8}$ & $5.3^{\mathrm{c}}$ & $5.0^{\mathrm{c}}$ & $7.0^{\mathrm{a}}$ & $5.8^{\mathrm{bc}}$ & $5.3^{\mathrm{c}}$ & $6.2^{\mathrm{ab}}$ & 0.001 & 0.45 \\
\hline $\mathbf{3 3}$ & $6.2^{\mathrm{b}}$ & $6.5^{\mathrm{b}}$ & $7.7^{\mathrm{a}}$ & $7.3^{\mathrm{a}}$ & $6.3^{\mathrm{b}}$ & $6.5^{\mathrm{b}}$ & $<0.001$ & 0.30 \\
\hline
\end{tabular}

${ }^{1}$ Litter score ranges from 10 (dry, friable) to 0 (wet/100\% plaque).

At $d$ 28, oat hulls and fish oil fed birds had improved litter score compared to the control diet. At d 33, oat hulls and lysozyme fed birds still had improved litter score compared to the control diet.

\subsection{Microbiota}

Microbiota composition and hierarchical clustering of jejunal and ileal digesta samples per pen at species level for d21 is presented in Figure 1. No large differences between pens were observed. For each sample, clustering of microbiota per treatment and per segment for $\mathrm{d} 21$ is presented in Figure 2. No (treatment) clustering in jejunum and ileum was seen. From the taxa-bars it was clear, that the ileum-jejunum samples were too much alike and that the microbiota composition/diversity was fairly similar for all treatments. This was the case for all taxonomic levels. Microbiota composition averaged per treatment per segment (d21) is presented in Figure 3. Small differences between treatments were observed. Dietary interventions including oat hulls and $\beta$-glucans tended to differ from the control, especially in ileum. From this it was clear, that by averaging and by clustering per tissue, there was no real clustering by treatment/group, indicating that nutritional interventions had no meaningful effect on the microbiota composition. Alpha diversity by Shannon index for ileum and jejunum is presented in Figure 4 and 5 , respectively. No significant effects of treatment on diversity index in jejunum was seen, indicating that the degree of diversity in microbiota composition in these segments was not affected by dietary treatments. Principal component analysis on microbiota in ileum and jejunum are presented in Figures 6 and 7, respectively. Figure 7 showed that according to the principal component analysis the ileal microbiota composition at $\mathrm{d} 21$ of the oat hulls treatment (green triangle) differed from data from the other experimental treatments, which were all centred around the origin. This is a general indication that the microbiota of the oat hulls fed birds differed from the other treatments. More specifically, a significant taxon-treatment association was found in the ileum within the genus Enterococcus (Figure 8), which was significantly higher in the oat hulls treatment $(8.1 \%)$ compared to the control $(2.5 \%)$ and fish oil $(3.5 \%)$ fed birds, mainly at the expense of Lactobacilli. 

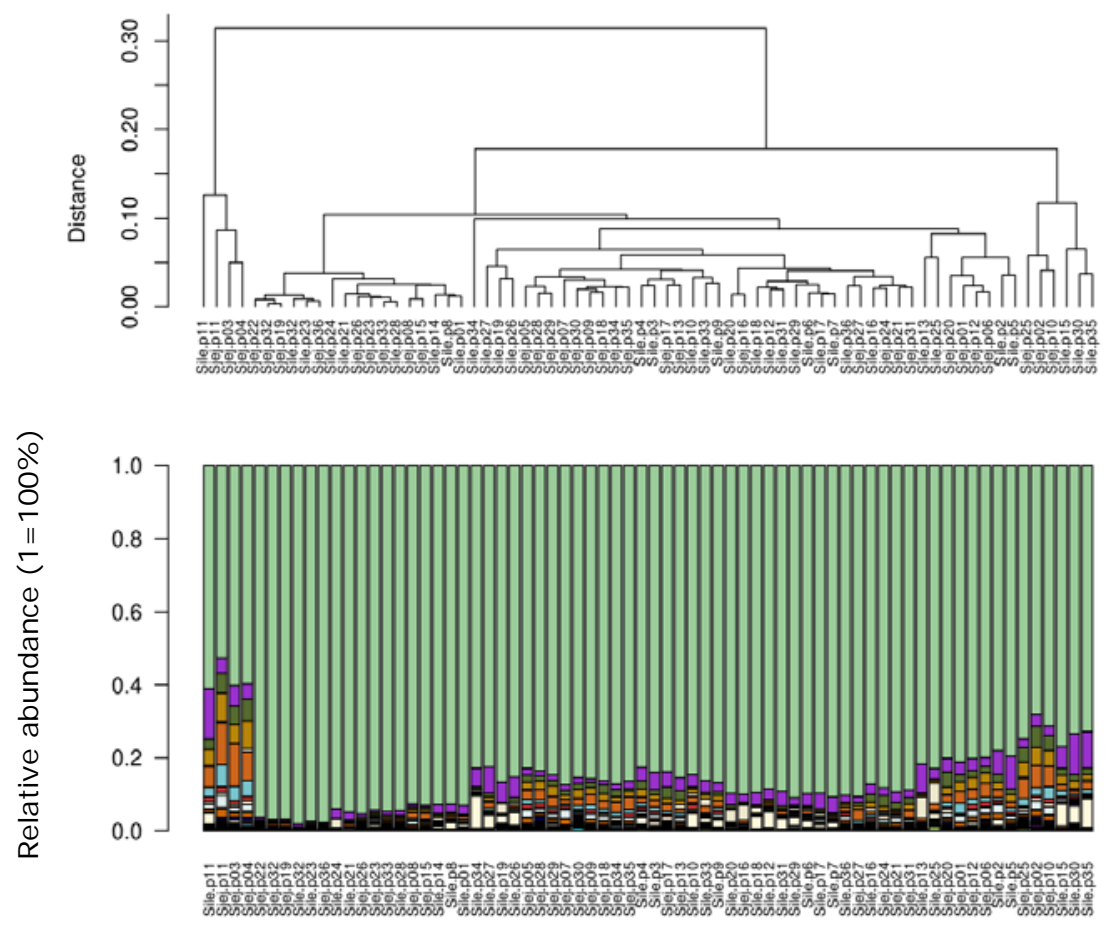

ㅁ﹎._Lactobacillaceae:g_Lactobacillus:s_

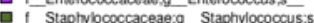

- Staphylbococcaceaerg Jeotgalicoccusis psychroph

I Streptococcaceae ig_Streptococcuss

- Aerococcaccae:?_Facklamias _

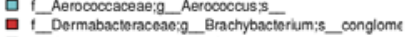

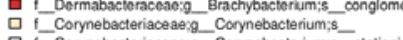

- Corynebacteriaceae;g Corynebacterium;s_stationit

a Carnobacteriaceae:g Trichococcuss.

- Enterobacteriaceae; $g^{3}$ -

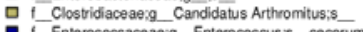

- Enterocoscacoae:g Enterococcusis cocorum

Figure 1 Microbiota composition of jejunal and ileal digesta samples per pen (species level, d21). The upper figure shows the percentage distance in microbiota composition between pens, and the lower figure the relative abundance $(1=100 \%)$ of the species per individual pen.

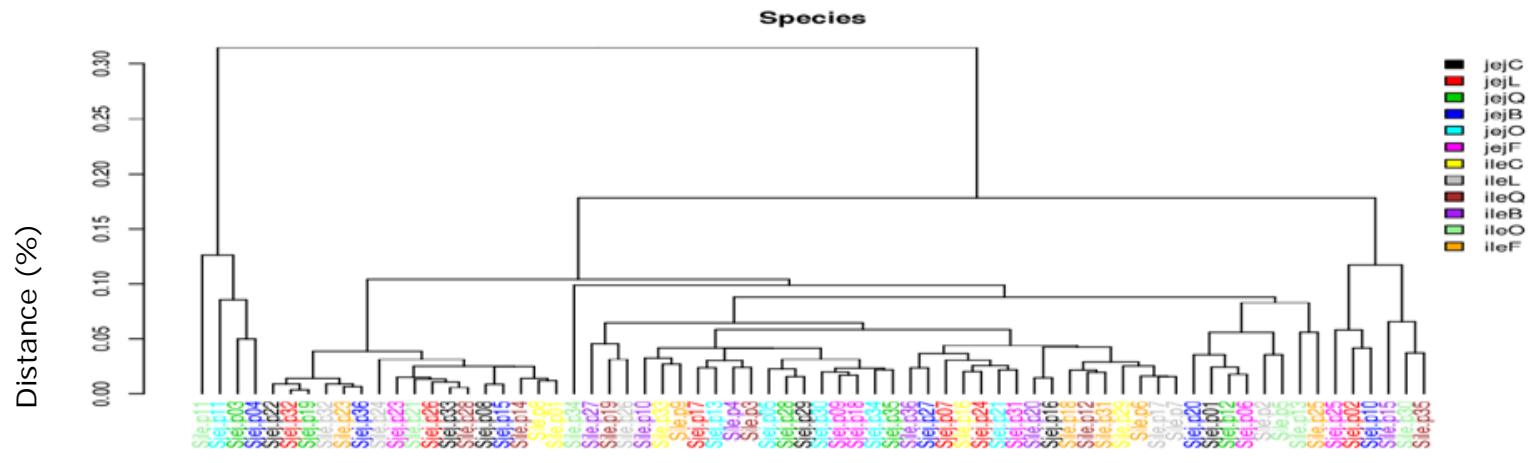

Figure 2 Hierarchical clustering of microbiota composition (percentage distance between pens) of jejunal and ileal digesta per treatment at pen level (d21). 

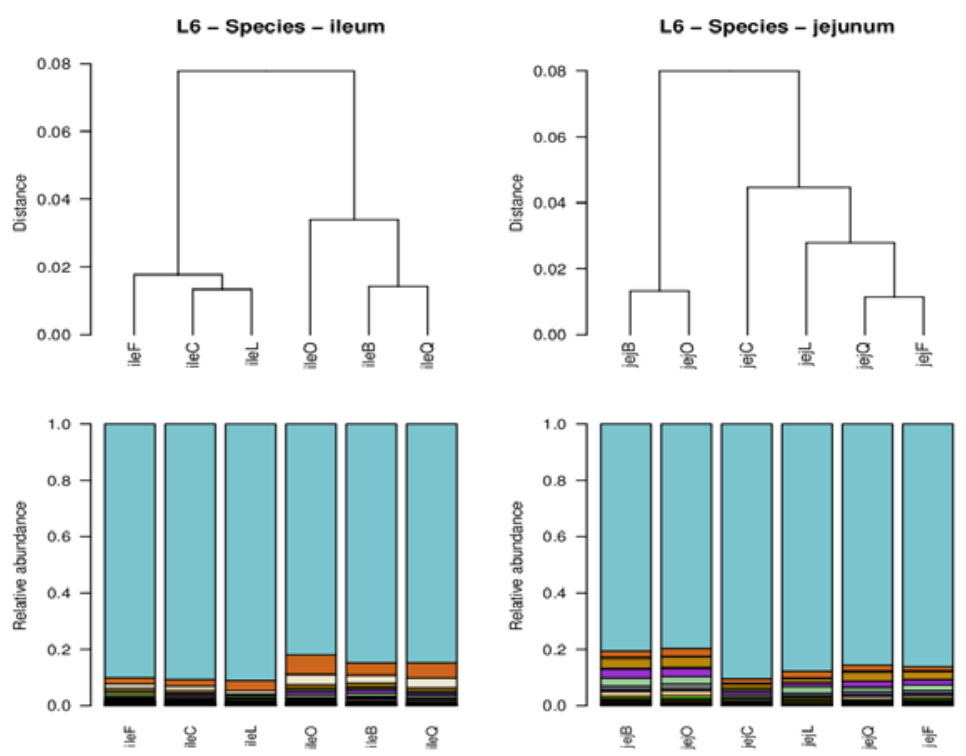

ㅁ﹎._Lactobacillaceae;g_Lactobacillus;s_

. Enterococcaceae; $g$ Enterococcus;s

f Straphylococcaceae;g Staphylococcus;s

I Enterobacteriaceae; is is

- f_. Staphylococcaceae;g_ Jeotgalicoccus;s psyc …Aerococcaceae;g_. Facklamia;s

- Corynebacteriaceae,g Corynebacterium;s

- I. Dermabacteraceae;g_Brachybacterium;s_co

Figure 3 l leal (left panel) and jejunal (right panel) microbiota composition averaged per treatment (d21). The upper figure shows the distance (\%) between treatments and the lower figure the relative abundance ( $1=100 \%$ ) of microbiota species per treatment.

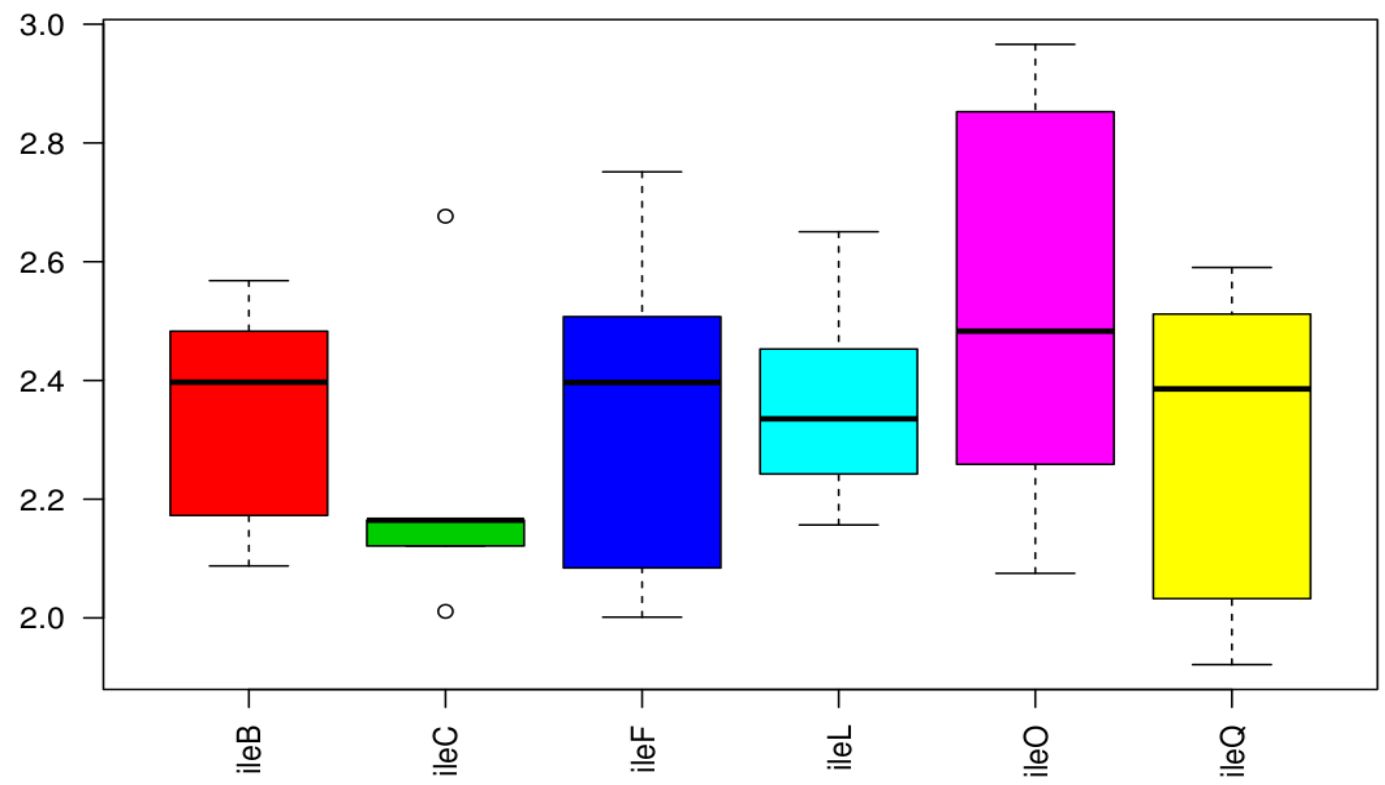

Figure 4 Diversity in ileal microbiota composition (d21), expressed by the Shannon diversity index. 


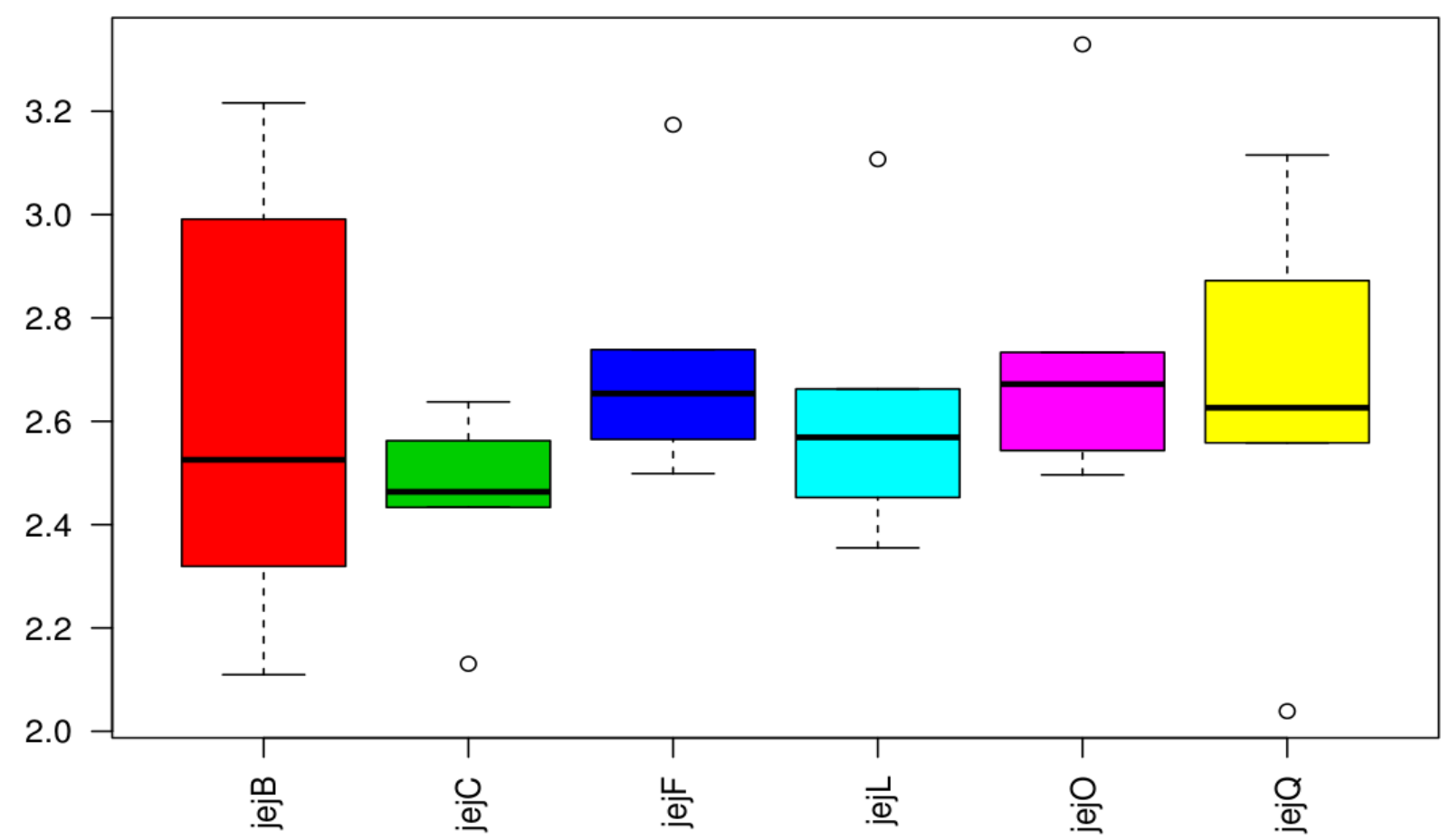

Figure 5 Diversity in jejunal microbiota composition ( $d 21$ ), expressed by the Shannon diversity index.
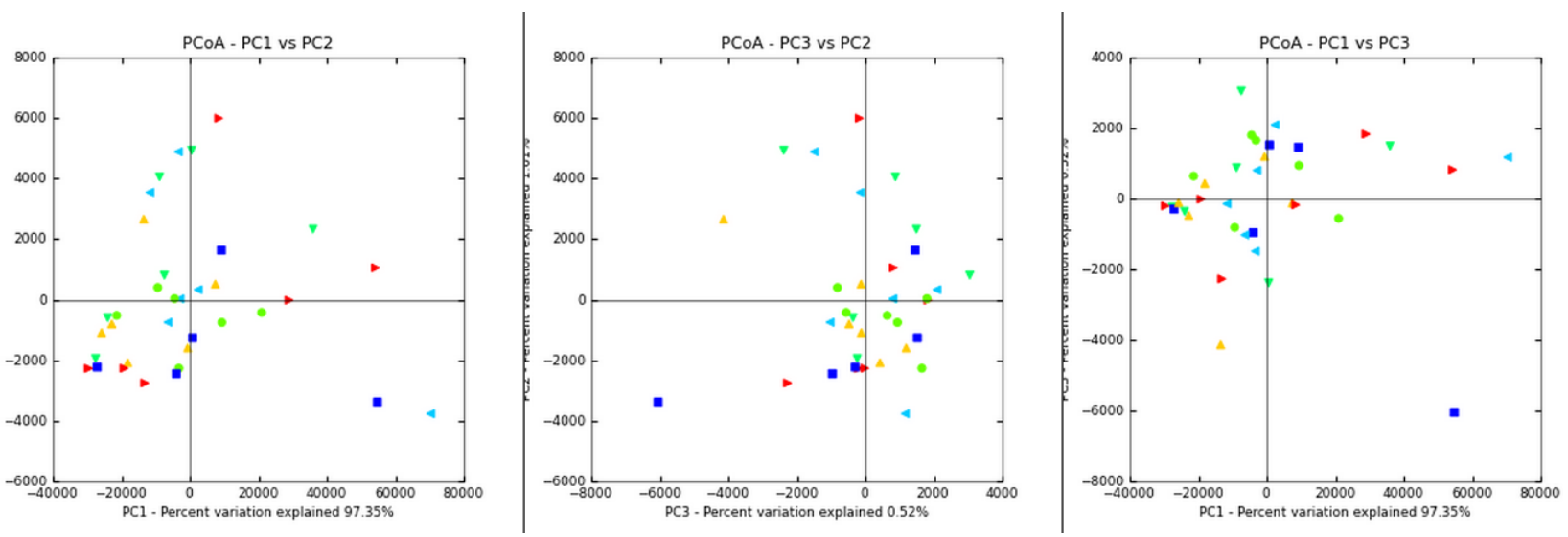

Figure 6 Principal component analysis on microbiota in jejunum (d21).
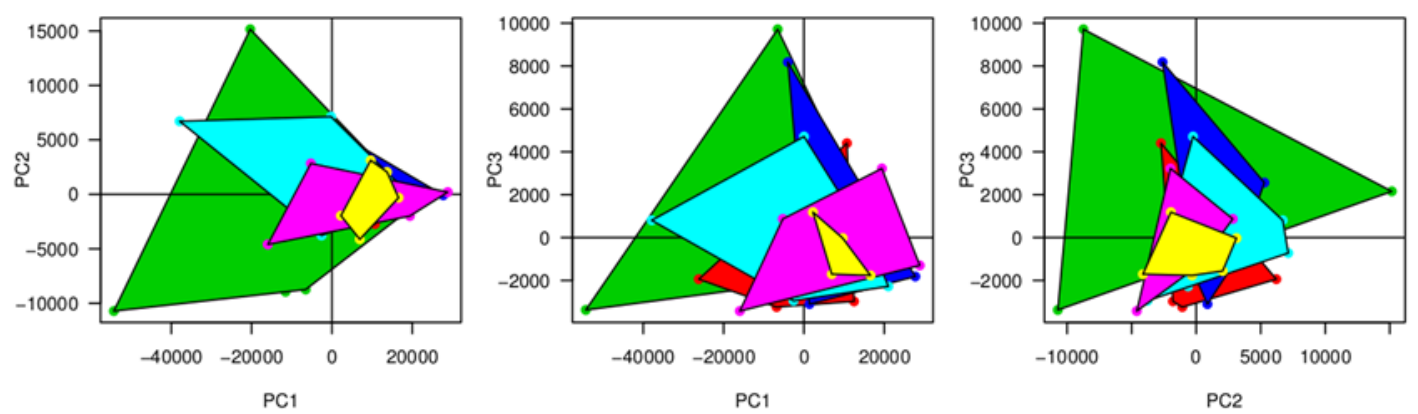

Legend

口 ileum_Oat_hul

ileum_Beta_glucane

- ileum_Fish_oil

민oum_Quercitine

- ileum_Lysozyme

ㅁ ileum_Control

Figure 7 Principal component analysis on microbiota in ileum (d21). 


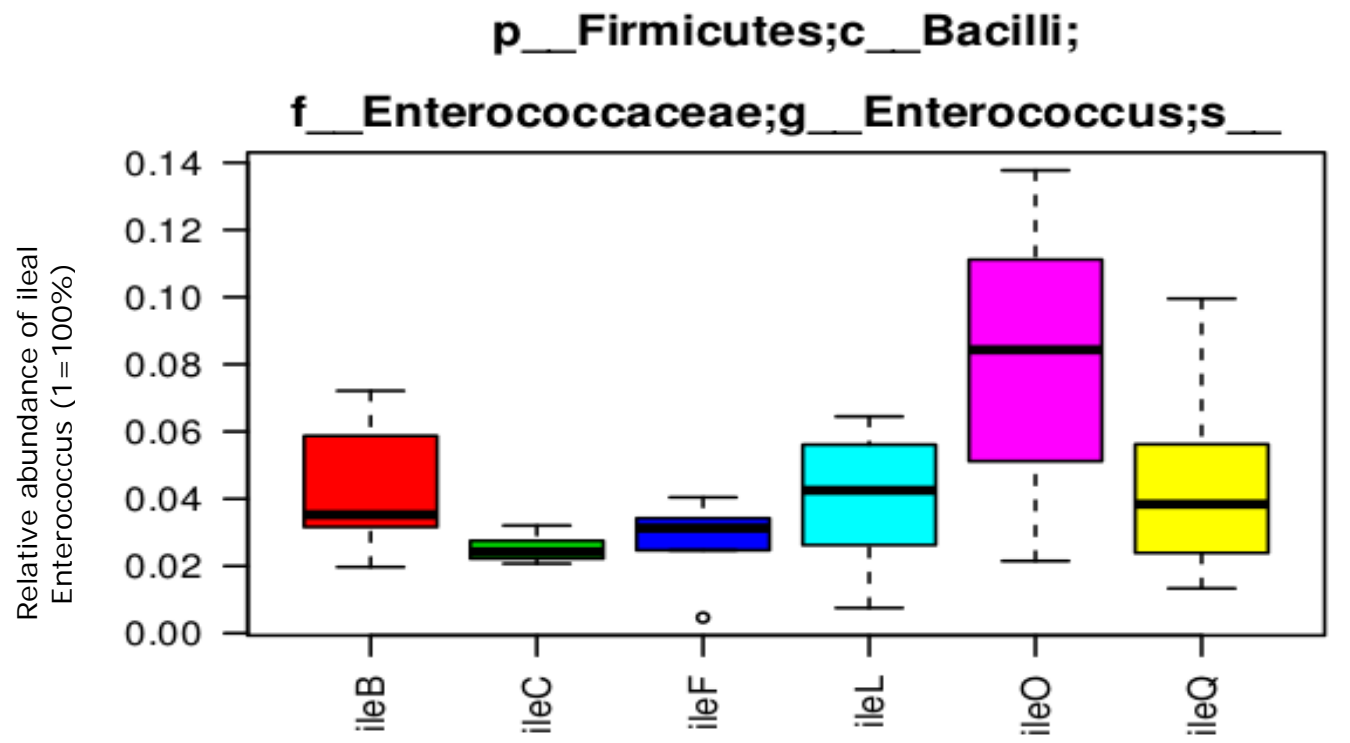

Figure 8 Relative abundance of ileal Enterococcus $(1=100 \%)$ per treatment $(d 21)$.

\subsection{Gut morphology}

Results for villus height $(\mu \mathrm{m})$ of jejunum and ileum presented per treatment for two different samplings ( $d 21$ and $\mathrm{d} 28$ ) are presented in Table 11 . No effect of treatments on villus height of jejunum on $\mathrm{d} 21$ and of ileum $(\mathrm{d} 21, \mathrm{~d} 28)$ was observed. Villus height of lysozyme fed birds in jejunum at d28 was decreased compared to the control and oat hulls $(P<0.005)$.

Table 11 Villus height $(\mu \mathrm{m})$ of jejunum and ileum presented per treatment for two different samplings ( $d 21$ and $d 28)$.

\begin{tabular}{lcccccccc} 
Days & Control & Quercetin & Oat hulls & Lysozyme & $\beta$-glucan & Fish oil & P-value & SE \\
Jej. 21 & 1388 & 1455 & 1477 & 1368 & 1422 & 1381 & 0.669 & 77.9 \\
\hline Jej. 28 & $1354^{\text {ab }}$ & $1260^{\text {abc }}$ & $1558^{\text {a }}$ & $1076^{\mathrm{c}}$ & $1306^{\text {abc }}$ & $1249^{\text {bc }}$ & 0.005 & 120.4 \\
\hline IL. 21 & 482 & 542 & 479 & 434 & 579 & 427 & 0.875 & 150.3 \\
\hline IL. 28 & 810 & 759 & 796 & 838 & 796 & 743 & 0.687 & 65.1 \\
\hline
\end{tabular}

Results for crypt depth $(\mu \mathrm{m})$ of jejunum and ileum presented per treatment for two different samplings (d21 and d28) are presented in Table 12. No effect of treatments on crypt depth of jejunum on $\mathrm{d} 21$ and of ileum (d21, d28) was observed. Crypt depth of lysozyme fed birds in jejunum at d28 was decreased compared to the control and other dietary interventions $(P<0.001)$.

Table 12 Crypt depth $(\mu \mathrm{m})$ of jejunum and ileum presented per treatment for two different samplings (d21 and d28).

\begin{tabular}{lcccccccc} 
Days & Control & Quercetin & Oat hulls & Lysozyme & $\beta$-glucan & Fish oil & P-value & SE \\
Jej. 21 & 323 & 274 & 335 & 301 & 291 & 305 & 0.800 & 45.3 \\
\hline Jej. 28 & $433^{\text {ab }}$ & $451^{\mathrm{a}}$ & $421^{\mathrm{ab}}$ & $307^{\mathrm{c}}$ & $405^{\mathrm{b}}$ & $457^{\mathrm{a}}$ & 0.001 & 39.8 \\
\hline IL. $\mathbf{2 1}$ & 142 & 160 & 150 & 126 & 166 & 129 & 0.902 & 43.8 \\
\hline IL. 28 & 216 & 222 & 208 & 257 & 218 & 210 & 0.651 & 32.1 \\
\hline
\end{tabular}

Results for Villus/crypt ratio of jejunum and ileum presented per treatment for two different samplings (d21 and d28) are presented in Table 13. No effect of treatments on villus/crypt ratio of jejunum on $\mathrm{d} 21$ and of ileum (d21, d28) was detected. Interventions deviated not significantly from the control in villus/crypt ratio in jejunum at $\mathrm{d} 28$, although villus/crypt ratio of the birds fed oat hulls tended to be higher as compared to the control. 
Table 13 Villus/crypt ratio of jejunum and ileum presented per treatment for two different sampling (d21 and d28).

\begin{tabular}{lcccccccc} 
Days & Control & Quercetin & Oat hulls & Lysozyme & $\beta$-glucan & Fish oil & P-value & SE \\
Jej. 21 & 5.0 & 5.7 & 5.1 & 5.3 & 5.3 & 5.1 & 0.970 & 0.81 \\
\hline Jej. 28 & $3.3^{\text {ab }}$ & $2.9^{\mathrm{bc}}$ & $4.0^{\mathrm{a}}$ & $3.8^{\mathrm{ab}}$ & $3.5^{\mathrm{ab}}$ & $2.9^{\mathrm{bc}}$ & 0.050 & 0.44 \\
\hline IL. 21 & 3.5 & 3.5 & 3.3 & 3.5 & 3.5 & 3.4 & 0.797 & 0.20 \\
\hline IL. 28 & 3.9 & 3.6 & 4.0 & 3.6 & 3.8 & 3.7 & 0.478 & 0.25 \\
\hline
\end{tabular}

Effects of dietary interventions and sampling day on average number of goblet cells per villi, total surface area of villi occupied by goblet cells $\left(\mu \mathrm{m}^{2}\right)$, average goblet cell size $(\mu \mathrm{m})$, average total villi surface area $\left(\mu \mathrm{m}^{2}\right)$, and goblet cell surface area relative to total villi surface area (\%) of jejunum and ileum in two sampling days (days 21 and 28 of age) are presented in Tables 14 to 18, respectively. Among the measured characteristics of goblets cells, significant effect of dietary interventions were seen on total surface area of villi occupied by goblet cells $\left(\mu \mathrm{m}^{2}\right)$ as well as average total villi surface area $\left(\mu \mathrm{m}^{2}\right)$ of jejunum. In jejunum, the total surface area of villi occupied by goblet cells $\left(\mu \mathrm{m}^{2}\right)$ and average total villi surface area $\left(\mu \mathrm{m}^{2}\right)$ were higher in chickens fed diet included oat hulls compared with other dietary interventions. 
Table 14 Effects of dietary interventions on average number of goblet cells per villi of jejunum and ileum in two sampling days (days 21 and 28 of age).

\begin{tabular}{|c|c|c|c|c|c|c|c|c|c|c|}
\hline Section and age of sampling (d) & Control & Quercetin & Oat hulls & Lysozyme & $\beta$-glucan & Fish oil & SE & $\begin{array}{l}\text { P-value } \\
\text { Treatment }\end{array}$ & $\begin{array}{c}\text { P-value } \\
\text { Day }\end{array}$ & $\begin{array}{l}\text { P-value } \\
\text { Trt x Day }\end{array}$ \\
\hline Jejunum & & & & & & & & & & \\
\hline Day 21 & 88.4 & 69.8 & 107.3 & 77.6 & 72.5 & 78.7 & 22.92 & \multirow{2}{*}{0.203} & \multirow[b]{2}{*}{$<0.001$} & \multirow[b]{2}{*}{0.997} \\
\hline Day 28 & 157.9 & 146.2 & 195.2 & 143.5 & 138.0 & 160.7 & 25.42 & & & \\
\hline \multicolumn{11}{|l|}{ Ileum } \\
\hline Day 21 & 46.1 & 61.0 & 53.3 & 41.7 & 57.3 & 43.9 & 13.0 & \multirow{2}{*}{0.875} & \multirow{2}{*}{$<0.001$} & \multirow{2}{*}{0.977} \\
\hline Day 28 & 112.9 & 110.6 & 108.5 & 110.2 & 110.8 & 104.8 & 13.5 & & & \\
\hline
\end{tabular}

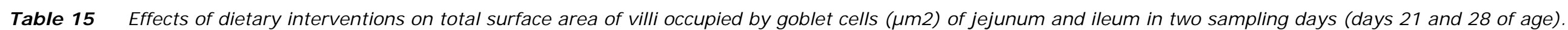

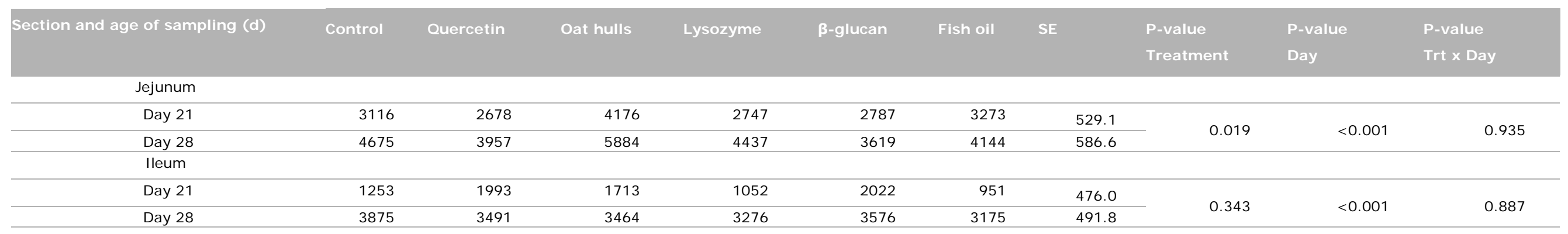

Table 16 Effects of dietary interventions on average goblet cell size ( $\mu \mathrm{m}$ ) of jejunum and ileum in two sampling days (days 21 and 28 of age).

\begin{tabular}{|c|c|c|c|c|c|c|c|c|c|c|}
\hline $\begin{array}{l}\text { Section and age of } \\
\text { sampling (d) }\end{array}$ & Control & Quercetin & Oat hulls & Lysozyme & $\beta$-glucan & Fish oil & SE & $\begin{array}{l}\text { P-value } \\
\text { Treatment }\end{array}$ & $\begin{array}{l}\text { P-value } \\
\text { Day }\end{array}$ & $\begin{array}{l}\text { P-value } \\
\text { Trt x Day }\end{array}$ \\
\hline \multicolumn{11}{|l|}{ Jejunum } \\
\hline Day 21 & 44.9 & 48.7 & 47.8 & 44.7 & 48.0 & 51.1 & 5.95 & \multirow{2}{*}{0.990} & \multirow{2}{*}{$<0.001$} & \multirow{2}{*}{0.934} \\
\hline Day 28 & 29.7 & 26.6 & 30.3 & 31.5 & 26.7 & 26.3 & 6.59 & & & \\
\hline \multicolumn{11}{|l|}{ Ileum } \\
\hline Day 21 & 24.0 & 30.6 & 28.8 & 22.3 & 36.2 & 15.1 & 6.68 & \multirow{2}{*}{0.540} & \multirow{2}{*}{0.224} & \multirow{2}{*}{0.826} \\
\hline Day 28 & 33.8 & 31.8 & 31.3 & 29.6 & 32.4 & 30.4 & 6.92 & & & \\
\hline
\end{tabular}


Table 17 Effects of dietary interventions on average total villi surface area ( $\mu \mathrm{m} 2$ ) of jejunum and ileum in two sampling days (days 21 and 28 of age).

\begin{tabular}{|c|c|c|c|c|c|c|c|c|c|c|}
\hline Section and age of sampling (d) & Control & Quercetin & Oat hulls & Lysozyme & $\beta$-glucan & Fish oil & SE & $\begin{array}{l}\text { P-value } \\
\text { Treatment }\end{array}$ & $\begin{array}{c}\text { P-value } \\
\text { Day }\end{array}$ & $\begin{array}{l}\text { P-value } \\
\text { Trt x Day }\end{array}$ \\
\hline \multicolumn{11}{|l|}{ Jejunum } \\
\hline Day 21 & 222358 & 212118 & 250921 & 225555 & 218541 & 226596 & 14928 & \multirow[b]{2}{*}{0.014} & \multirow[b]{2}{*}{0.659} & \multirow[b]{2}{*}{0.279} \\
\hline Day 28 & 239986 & 219142 & 283921 & 199146 & 184542 & 238698 & 16535 & & & \\
\hline \multicolumn{11}{|l|}{ Ileum } \\
\hline Day 21 & 58609 & 69226 & 69256 & 53767 & 79243 & 40505 & 16937 & \multirow{2}{*}{0.875} & \multirow{2}{*}{$<0.001$} & \multirow{2}{*}{0.823} \\
\hline Day 28 & 123879 & 122054 & 112071 & 124141 & 117799 & 118372 & 17547 & & & \\
\hline
\end{tabular}

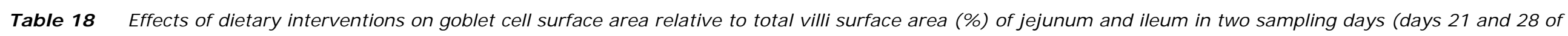
age).

\begin{tabular}{|c|c|c|c|c|c|c|c|c|c|c|}
\hline Section and age of sampling (d) & Control & Quercetin & Oat hulls & Lysozyme & $\beta$-glucan & Fish oil & SE & $\begin{array}{l}\text { P-value } \\
\text { Treatment }\end{array}$ & $\begin{array}{c}\text { P-value } \\
\text { Day }\end{array}$ & $\begin{array}{l}\text { P-value } \\
\text { Trt x Day }\end{array}$ \\
\hline \multicolumn{11}{|l|}{ J ejunum } \\
\hline Day 21 & 1.386 & 1.313 & 1.744 & 1.224 & 1.298 & 1.446 & 0.2292 & \multirow{2}{*}{0.618} & \multirow[b]{2}{*}{$<0.001$} & \multirow{2}{*}{0.535} \\
\hline Day 28 & 1.955 & 1.807 & 2.083 & 2.453 & 1.989 & 1.772 & 0.2542 & & & \\
\hline \multicolumn{11}{|l|}{ lleum } \\
\hline Day 21 & 1.828 & 2.403 & 1.943 & 1.723 & 2.324 & 1.800 & 0.360 & \multirow{2}{*}{0.627} & \multirow{2}{*}{$<0.001$} & \multirow{2}{*}{0.947} \\
\hline Day 28 & 3.193 & 3.055 & 3.081 & 2.788 & 3.096 & 2.829 & 0.373 & & & \\
\hline
\end{tabular}




\subsection{Gene expression}

Based on the principal component analysis (PCA), no significant effects of treatments on expression of genes was observed in jejunal and ileal tissue. Figure 9 shows the PCA 3D plot of gene expressions. One dot represents the overall expression data of a pooled tissue sample of six birds per pen. Clustering of gene expressions in the jejunum substantially differed from the ileum, indicating the functional differences between both segments. Within the gut sections, no clear differences in clustering of expressed genes occurred, showing that the dietary interventions in general had a limited effect on the biological processes in intestinal tissue. Nevertheless, dietary treatments affected a few specific biological processes in the ileum as presented in Table 19. Compared to the control birds, the genes related to growth-factor-activity pathway were higher expressed in chicken fed the diet including $\beta$-glucan (FDR q-value $=0.026$ ), whereas the genes related to anion-transmembranetransporter-activity pathway in the quercetin and oat hulls included diet were lower expressed (FDR qvalue $=0.016$ ). Individual genes in these pathways had low fold change values and high adjusted $\mathrm{P}$ values, and therefore no indications were found that the individual genes in these pathways were related to immunity.

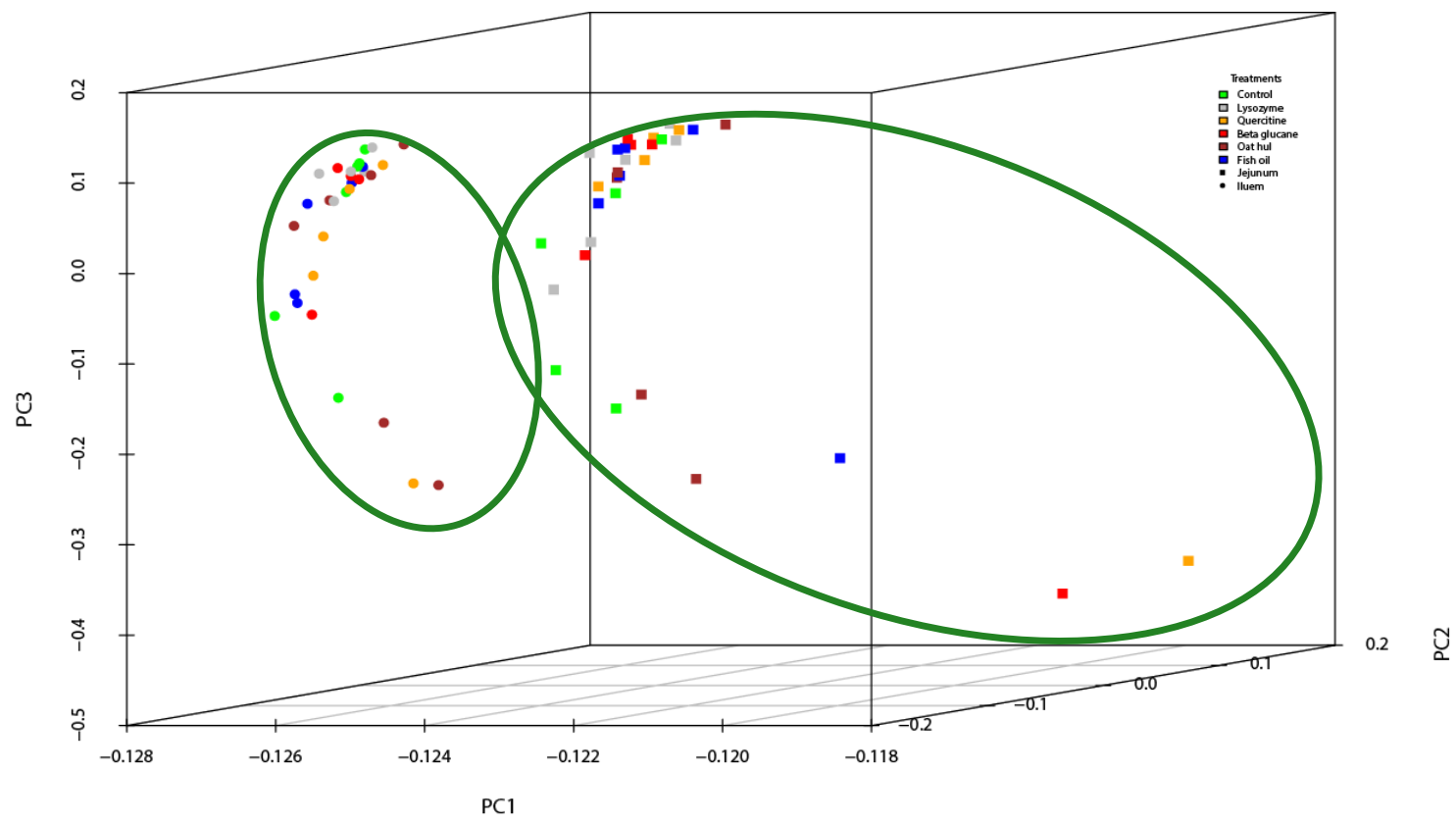

Figure 9 Principal Component Analysis 3D plot gene expressions (PCA 3D plot) in jejunum and ileum (d21). Squares represent jejunal samples and circles ileal samples. 
Table 19 Annotation of the different expressed genes per treatment as compared to the control treatment in ileal tissue to the related biological processes ( $d 21)$.

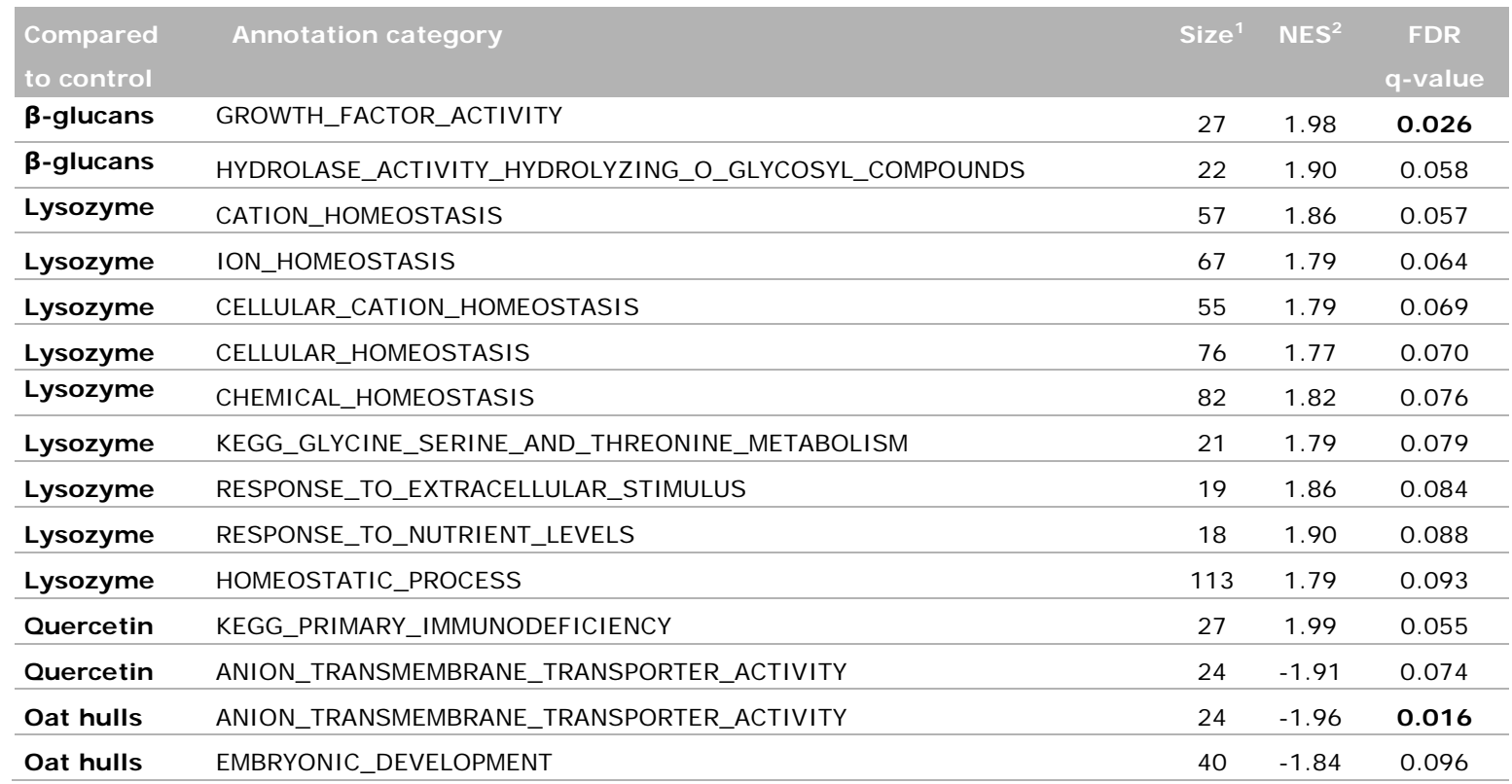

${ }^{1}$ Size $=$ number of different expressed genes involved in the specific annotation category.

${ }^{2}$ NES stands for Normalized Enrichment Score. It is a measure for over-representation of classes of genes in the tissues and may have an association with disease phenotypes

\subsection{Organ weights}

Results for the relative weight of bursa of Fabricius and spleen to body weight per treatment for two different samplings ( $d 21$ and d28) are presented in Table 20 and 21, respectively. The interaction between treatment and sampling day on relative weight of bursa was significant $(P=0.005)$. At $d 21$, relative weight of bursa of birds fed fish oil was increased compared to the control group, whereas relative bursa weight of fish oil fed birds did not differ from the control at d28. There was no significant effect of treatment on relative weight of spleen, but the effect of sampling day was significant $(P<0.001)$. Relative weight of spleen was higher in $\mathrm{d} 28$ compared to $\mathrm{d} 21$. 
Table 20 Effects of nutritional interventions on relative weight of bursa of Fabricius to body weight in two sampling days (day 21 and 28 of age).

\begin{tabular}{|c|c|c|c|c|c|c|c|c|c|c|}
\hline $\begin{array}{l}\text { Section and } \\
\text { age of } \\
\text { sampling } \\
\text { (d) }\end{array}$ & Control & Quercetin & Oat hulls & Lysozyme & $\beta$-glucan & Fish oil & SE & $\begin{array}{l}\text { P-value } \\
\text { Treat-ment }\end{array}$ & $\begin{array}{l}\text { P-value } \\
\text { Day }\end{array}$ & $\begin{array}{l}\text { P-value } \\
\text { Trt x Day }\end{array}$ \\
\hline Day 21 & $2.19^{\mathrm{abcd}}$ & $2.43^{\mathrm{de}}$ & $2.22^{\mathrm{bcd}}$ & $2.20^{\mathrm{abcd}}$ & $2.31^{\text {cde }}$ & $2.54^{\mathrm{e}}$ & 0.530 & 0.764 & $<0.001$ & 0.005 \\
\hline Day 28 & $2.14^{\mathrm{abc}}$ & $2.16^{\mathrm{abc}}$ & $2.33^{\text {cde }}$ & $2.15^{\mathrm{abc}}$ & $2.04^{\mathrm{ab}}$ & $1.95^{\mathrm{a}}$ & & & & \\
\hline
\end{tabular}

Table 21 Effects of nutritional interventions on relative weight of spleen to body weight in two sampling days (day 21 and 28 of age).

\begin{tabular}{|c|c|c|c|c|c|c|c|c|c|c|}
\hline $\begin{array}{l}\text { Section and } \\
\text { age of } \\
\text { sampling (d) }\end{array}$ & Control & Quercetin & Oat hulls & Lysozyme & $\beta$-glucan & Fish oil & SE & $\begin{array}{l}\text { P-value } \\
\text { Treatment }\end{array}$ & $\begin{array}{l}\text { P-value } \\
\text { Day }\end{array}$ & $\begin{array}{l}\text { P-value } \\
\text { Trt x Day }\end{array}$ \\
\hline Day 21 & $1.11^{\mathrm{b}}$ & $1.18^{\mathrm{b}}$ & $1.14^{\mathrm{b}}$ & $1.12^{\mathrm{b}}$ & $1.16^{b}$ & $1.12^{\mathrm{b}}$ & \multirow[b]{2}{*}{0.280} & \multirow[b]{2}{*}{0.967} & & \multirow[b]{2}{*}{0.316} \\
\hline Day 28 & $1.36^{\mathrm{a}}$ & $1.25^{\mathrm{a}}$ & $1.27^{\mathrm{a}}$ & $1.26^{\mathrm{a}}$ & $1.22^{\mathrm{a}}$ & $1.33^{\mathrm{a}}$ & & & $<0.001$ & \\
\hline
\end{tabular}




\section{Discussion}

\section{Nutritional challenge by dietary rapeseed inclusion}

In the present study, rapeseed meal at a level of $250 \mathrm{~g} / \mathrm{kg}$ was included in the experimental diets to cause nutritional challenge, because the in rapeseed meal present antinutritional factors hampers nutrient intake by the gut. The main components of rapeseed include protein, carbohydrates (i.e. simple sugars, sucrose, oligosaccharides, starch), fibre (i.e. NSP, lignin with associated polyphenols, glycoproteins), fat, and ash. As a consequence of the small size and high oil content in rapeseed, the resulting meal contains a relatively high proportion of fibre. The crude fibre (Kocher et al., 2000; Mawson et al., 1993), acid detergent fibre (ADF), neutral detergent fibre (NDF), and total dietary fibre values for rapeseed are higher than those of soybean meal due to a much higher content of lignin with associated polyphenols (tannins). The NSP, which include $\beta$-glucans, arabinoxylans and pectins, may decrease nutrient digestibility (Downey and Bell, 1990), mainly on crude fat and amino acids (Knudsen, 1997), as well as the performance of broiler chickens fed diets with high levels of rapeseed meal (Bedford, 2000; Koncicki et al. 1991; Haščik et al., 1994; Wetscherek et al., 1993). Rapeseed non-digested protein at ileal level may increase the amount of undigested amino acids reaching the hindgut that in turn may enhance proteolytic fermentation by resident microbiota (Libao-Mercado et al., 2009). As a side effect, hindgut protein fermentation can even further negatively affect performance of broilers due to the formation of toxic compounds such as amines, ammonia, skatole, or indoles (Gabriel et al., 2005). Rapeseed products have other nutritionally unfavourable substances such as glucosinolates, sinapine, tannin, erucic acid and phytate (Ciska and Kozowska, 1998; Korol et al., 1994; Mustapić and Pospišil, 1995).

During the period that the experimental grower diets were provided, the performance level of the broilers in the present study was below the Ross 308 performance standards of male broilers (Ross, 2012). The poor general performance of broilers was assumed to be mostly due to insertion of a high level of rapeseed meal to the diets, resulting in retardation of body weight gain and less efficient feed conversion. After the switch to the commercial finisher diets, compensatory growth occurred, resulting in body weights at d33 that met the Ross (2014) standard.

\section{Performance and litter quality}

Feed intake of broilers fed the diet including oat hulls and lysozyme was reduced during the first week of the growing period, and birds adapted to consume diets including oat hulls and lysozyme on the week after. During the first week of the growing period, temporary reduced feed intake of broilers fed the diet including oat hulls may partly due to the high dietary percentage of crude fat ( $10 \mathrm{vs.} 13 \%)$, which can in turn reduce voluntary feed intake especially in young chicks (Fuller and Rendon, 1977). On the other hand, chicks fed the diet including oat might not able to compensate in feed intake because of physical limitation. During the first week of growing period, a trend of decreased BWG of broilers fed the diet including lysozyme, oat hulls and fish oil was observed. The decreased BWG of broilers fed the diet including oat hulls is mainly due to reduced feed intake which was mentioned before. There is no clear reason for the decreased BWG of broilers fed the diet including lysozyme, and fish oil. Over the second week of the growing period, broilers fed the diet including lysozyme showed increased BWG compared to the control and birds fed the diets including quercetin and $\beta$-glucan. Broilers fed the diets including fish oil and oat hulls also showed increased BWG during the second week of growing period. It seems that broilers fed the diets including lysozyme, oat hulls and fish oil had compensatory growth, and no significant difference in BWG between nutritional interventions considering the whole growing period were observed. Improved FCR in broilers fed the diets supplemented with lysozyme, oat hulls and fish oil was seen during the second week of the growing period. Improved FCR in broilers fed the oat hulls diet may be partly explained based on the studies by Qaisrani et al (2014 and 2015), where coarse diets improved gut integrity (villus height) and gizzard development.

The five different nutritional interventions applied in this study; quercetin, oat hulls, $\beta$-glucan, lysozyme, and fish oil; have also been used in previous investigations as immuno-modulatory agents. Based on the literature, the effectiveness and action mechanism of these dietary additives differ. In agreement with the results of the current study in terms of improved FCR in broilers fed the diets supplemented with oat hulls during the second week of the growing period, benefits of dietary inclusion of insoluble fibre on growth have been demonstrated with mash (Gonzalez-Alvarado et al., 2007; Jimenez-Moreno et al., 2011), whereas no effect has been observed with pellets (Amerah et al., 2009a; Hetland et al., 2003; van der Hoeven-Hangoor et al., 2014). In addition, Jimenez-Moreno et al 
(2015) reported that the inclusion of oat hulls or sunflower hulls into low fibre diets was beneficial for improving broiler performance. Jimenez-Moreno et al (2009b) who arranged factorial three sources of fibres (none; $3 \%$ oat hulls, and $3 \%$ sugar beet pulp) and 2 fat sources ( $5 \%$ soybean oil and $5 \%$ yellow grease) reported improved performance and nutrient digestibility in young chicks, especially when saturated fats were used. In our study, the crude fat (soya oil which has mostly unsaturated lipids) percentage of diet including oat hulls was higher than the other diets, which in turn affected feed intake and FCR of broilers. On the other hand, improved FCR in broilers fed the oat hulls diet may be partly due to the effect of oat hulls in increasing the coarseness of the diet (Qaisrani et al., 2014 and 2015).

The effect of dietary fibre on gizzard development was found to depend on fibre source and its particle size (Amerah et al., 2009; Hetland et al., 2005; Mateos et al., 2012; Svihus, 2011) Sacranie et al (2012) showed that the addition of hulls (consisting of equal weights of hulls from oats and barley) increased gizzard weight and content and lowered gizzard $\mathrm{pH}$. In the current experiment, gizzard weight and gizzard pH were not measured. FCR of the oat hulls fed birds during the second week of the growing period, however, significantly improved compared to the control group. This might be the result of increased gizzard weight and improved gizzard functioning, which adapted to the supplementation of the oat hulls diet. In agreement with our finding, improved feed conversion efficiency, corrected for insoluble fibre contents, was detected in broilers by inclusion of oat hulls in diets based on whole or ground wheat (Hetland et al., 2003).

Similar to the current study, Goliomytis et al (2014b) also added quercetin to feed and observed no effect on body weight and feed intake of broilers; but poorer FCR values and relative heart weight were obtained with increasing levels of dietary quercetin.

Oat hulls and fish oil fed birds had improved litter score compared to the control diet at $\mathrm{d} 28$ and oat hulls and lysozyme fed birds still had improved litter score compared to the control diet at $d 33$. In agreement with our study, Van der Klis and de Lange (2013) reported that the inclusion of 5.0\% oat hulls in iso-nutritive diets reduced water-to-feed ratio in broilers from 1 to $21 \mathrm{~d}$ of age. In addition, van der Hoeven-Hangoor et al (2014) reported that the inclusion of $2.5 \%$ coarse oat hulls in a wheat and soybean meal based diet with $2.4 \%$ crude fibre reduced excreta and litter moisture content in broilers.

It can be concluded that the dietary interventions had limited effect on performance levels of the birds. Litter score improved by feeding oat hulls and fish oil (d28), and oat hulls and lysozyme (d33), which might be in indication of better functioning of the GIT.

\section{Gut microbiota}

Gut microbiota have an important role in broiler health and performance (Gordon and Pesti 1971; Hammons et al., 2010; Klosterbuer et al., 2011, Torok et al., 2011b). Although in the present study, small differences between treatments were observed in terms of microbiota composition at day 21 , both in jejunum and ileum, but in general the effects of the nutritional interventions were absent or small. This might be related to the timing of application of the interventions, being d14 - 28 of age. Supplementation of oat hulls tended to differ from the control, especially in ileum. It has been demonstrated that several factors can influence the host's gut microbiota, including age, genetics, housing environment and stress, although the greatest effecting factor by far is the host's diet (Lu et al., 2003; Burkholder et al., 2008; Torok et al., 2009, 2011b; Lumpkins et al., 2010). Nevertheless, changes in gut microbiota due to nutritional intervention does not always cause altered broiler performance (Gunal et al., 2006; Pedroso et al. 2006; Geier et al. 2009). The primarily focus in this study was to improve immune competence and not performance, among others by affecting microbiota composition. Multiple studies have been conducted to measure the effect of dietary manipulation on profile of the gut microbial community applying microbiological culturing techniques, culture-independent molecular techniques and indirect measurement of bacterial metabolic products (Bjerrum et al., 2006; Choct et al., 1999; Hubener et al., 2002; Zhu et al., 2002; Yin et al., 2010). The molecular techniques, including denaturing gradient gel electrophoresis, terminal restriction fragment length polymorphism, pyrotag sequencing and phylogenetic microarrays have been also used to investigate microbial community structure (Amend et al. 2010; Zhou et al., 2011; Fraher et al., 2012). Torok et al (2013) developed quantitative polymerase chain reaction (qPCR) assays to five potential performance-related bacteria (Lactobacillus salivarius, L. crispatus, L. aviarius, Gallibacterium anatis and Escherichia coli) and generic eubacteria. They detected that L. salivarius, L. crispatus, L. aviarius, E. coli and total eubacterial numbers were altered by diet, environment (litter), and/or sex of birds. In addition, Lactobacilli and total Eubacteria were decreased in birds that were more feed efficient, but E. coli and G. anatis was found not to be consistently linked with broiler performance.

In the current study, qPCR $16 \mathrm{~S}$ sequencing technique was applied to determine all available gut microbiota at genus level. Alpha diversity by Shannon index showed a trend to a more diverse microbiota composition in the birds fed oat hulls. At genus-level, principal component analysis on 
microbiota of ileum also showed that the diet included oat hulls was more separated from the cluster of the other samples, which were all centred around the origin. Higher abundance of Enterococcaceae was observed in ileum of birds fed the diet including oat hulls compared to the control and the fish oil included diets. The order Lactobacillae includes the family Enterococcaceae with four genera: Enterococcus, Melissococcus, Tetragenococcus, and Vagococcus. They can be found in diverse environments. In general, the Enterococcaceae are fastidious, and consequently, they thrive in environments where various nutritional needs are provided, usually by other living or dead organisms. In addition to the intestinal tracks of mammals, birds, fish, and insects, they can be recovered from decaying plant and animal material. Several Enterococcus species also produce lactic acid by homofermentative glucose metabolism. Enterococci are routinely cultivated on rich media with occasional pigment production and haemolysis (Palmer et al. 2012). Distinct strains of E. faecium and E. faecalis account for virtually all clinical infections caused by Enterococcaceae, particularly in nosocomial settings (Fisher and Phillips 2009). A number of Enterococcus species have been successfully used as probiotics for the treatment of diarrhea in humans and farm animals (Franz et al. 2011).

Lactobacillus is the major genus found in the ileum $(70 \%)$, whereas the other genera include Clostridiaceae (11\%), Streptococcus (6.5\%) and Enterococcus (6.5\%) (Lu et al., 2003). The microbiota is influenced by dietary ingredients such as medium chain fatty acids that decreased the growth of gram positive Firmicutes and some other species including Lactobacillus, Micrococcaceae and Enterococcaceae, whereas the growth of gram negative bacteria is increased (Van Der HoevenHangoor et al., 2013). The latter authors related the change in microbiota population with higher dietary concentrations of medium chain fatty acids to the sensitivity of gram positive compared with gram negative bacteria. The higher level of crude fat (especially from soya oil) of the oat hulls included diet compared to other diets as well as higher amount of insoluble fibres might cause the higher abundance of Enterococcaceae observed in ileum of the birds. In line with our findings, Amerah et al (2009) showed that the microbial composition of birds fed diets supplemented with whole wheat or wood shavings differed from birds fed the control of cellulose supplemented diet.

In a study by Zhang et al (2010), a lysozyme-based antimicrobial blend was very effective in reducing negative health effects in broilers after necrotic enteritis challenged with Eimeria maxima and Clostridium perfringens. In the current study, Lysozyme addition did not affect the jejunal and ileal microbiota composition of healthy broilers.

Supplementation of $\beta$-glucans showed a slight trend to differ from the control, especially in ileum. In trying to explore the effect of oligosaccharides as nutritional intervention on gut microbiota, it has been detected that mannan-oligosaccharide linked with improved gut health, indicated by increased populations of beneficial bacteria such as lactobacilli and bifidobacteria in the guts of broilers and turkeys, while reducing the populations of Salmonella and E. coli (Sims et al., 2004; Baurhoo et al., 2007b; Brummer et al., 2010).

It can be concluded $\mathrm{f}$ jejunum and ileum had similar microbiota compositions. Nutritional interventions, however, only slightly affected the overall microbiota composition within and between jejunum and ileum. Only feeding oat hulls affected ileal microbiota composition, as shown by an increased amount of Enterococcaceae at the expense of Lactobacillae, indicating that oat hulls good have the capacity to affect immune competence.

\section{Gut morphology}

No effect of nutritional interventions on villus height of jejunum on d21 and of ileum (d21, d28) was observed. Villus height and crypt depth of lysozyme fed birds in jejunum at d28, however, were decreased compared to the control. Villi height reflects the absorptive capacity of the intestine (Teirlynck et al., 2009). Interventions deviated not significantly from the control in villus/crypt ratio in jejunum at $\mathrm{d} 28$, although villus/crypt ratio of the birds fed oat hulls tended to be higher as compared to the control, so it seems that the birds in oat hulls group adapted to use the diet with higher amount of fibre compared to the other dietary groups. Jiménez-Moreno et al (2013b) evaluated the effects of inclusion of oat hulls $(\mathrm{OH})$ and sugar beet pulp (SBP) in the diet on the development of the gastrointestinal tract in broilers from 1 to 18 days of age and detected reduced villus height at $d 12$ with SBP inclusion, but no effects were detected with $\mathrm{OH}$. In addition, the inclusion of up to $75 \mathrm{~g} \mathrm{OH}$ or $\mathrm{SBP} / \mathrm{kg}$ in low fibre diets increased the relative weight of the GIT and reduced digesta $\mathrm{pH}$ of the gizzard. Sadeghi et al (2015), reported a decreased effect of sugar beet pulp (SBP) on villus height in the duodenum and ileum compared with control, whereas no influence of rice hulls (RH), or combination of SBP and RH (SBP/RH) was detected. Supplementing soluble fibre has been reported to reduce villus height in broilers given $50 \mathrm{~g} / \mathrm{kg}$ xanthan ( $\mathrm{ji}$ et al., 2001). No difference in jejunal villus height was observed using higher or equal ratios of insoluble to soluble fibres (Saki et al., 2011), indicating that insoluble fibres are not detrimental for jejunal villus height. Qaisrani et al. (2014 and 
2015) demonstrated that broilers fed coarse rapeseed meal based diets had heavier gizzards and lower relative empty weights of the crop, duodenum, jejunum, and ileum compared with those fed the fine diets. In addition, dietary coarseness resulted in greater ileal protein digestibility, lower gizzard $\mathrm{pH}$, greater villus height, lower crypt depth, reduced cecal branched chain fatty acids and lower biogenic amines in the cecal digesta compared with chickens fed the fine diets. In the study by Gao et al., (2008), supplementation with yeast culture (YC) increased villus height linearly, crypt depth in the duodenum, jejunum and ileum, and villus height to crypt depth ratio in duodenum, but decreased villus height to crypt depth ratio in jejunum and ileum. In the current experiment, however, dietary supplementation with $\beta$-glucans did not affect villus height in jejunum and ileum. Mannanoligosaccharide and 1,3/1,6 $\beta$-glucan are components of the yeast cell wall (Morales-Lopez et al., 2009; Talbott, 2012) that modulate immunity (An et al., 2008; Cox et al., 2010; Shashidhara and Devegowda, 2003), promote growth of intestinal microflora (Spring et al., 2000; Stanley et al., 2000), and increase growth (Parks et al., 2001). Microbiota composition of the $\beta$-glucan fed birds, however, was not affected. Average total villi surface area $\left(\mu \mathrm{m}^{2}\right)$ was affected by dietary interventions in two sampling days (days 21 and 28 of age). Mannan-oligosaccharide has been linked with improved gut health, indicated by increased villi length and the number of goblet cells of broilers and turkeys (Sims et al., 2004; Baurhoo et al., 2007; Brummer et al., 2010). Shikha-Bhatia et al (2015) indicated that galacto-oligosaccharides may enhance mucosal barrier function through direct stimulation of intestinal goblet cells. In jejunum, the total surface area of villi occupied by goblet cells $\left(\mu \mathrm{m}^{2}\right)$ and average total villi surface area $\left(\mu \mathrm{m}^{2}\right)$ were higher detected in chickens fed diet included oat hulls compared with other dietary interventions. Rezaei et al (2011) showed that dietary supplementation with micronized insoluble fibre resulted in dose dependent increases in the ileal villus height:crypt depth ratio and number of goblet cells in male broilers. Increased intestinal villus height, villus thickness, villus height: crypt depth ratio and number of goblet cells was detected in quails ( 7 to 35 day of age) fed diet included processed rice hulls (Rezaei et al., 2014) which is in agreement with the current results. These findings show that feeding insoluble fibres to broilers might improve gut morphology, which is an indication of both good gut health and absorptive capacity, which could be indirectly beneficial for the immune competence of the birds. Further research is required to unravel the mechanisms behind, especially if the insoluble fibres are provided from day-old onwards.

\section{Gut gene expression}

The information presenting in this section about the gene activity/functionality are related to human data, because more and better gene annotation is available. In the present study, no significant effect of the nutritional interventions on expression of genes was observed in jejunum. Compared to the control birds, the genes related to growth factor activity were expressed more in the $\beta$-glucans included diet. Relation between $\beta$-glucans and growth factor activity and wound healing has been welldocumented. Wei et al (2002) examined the effect of (1-3)- $\beta$-D-glucan phosphate, a highly purified water-soluble glucan isolated from Saccharomyces cerevisiae, on activation of the transcription factors activator protein- 1 and specificity protein- 1 in normal human dermal fibroblasts and showed that $\beta$ glucan stimulated fibroblast expression of neurotrophin 3, platelet derived growth factor $A$, platelet derived growth factor B, fibroblast growth factor acidic, fibroblast growth factor basic, transforming growth factor alpha, transforming growth factor beta and vascular endothelial growth factor mRNA. Wound healing is an immune mediated event (DiPietro, 1995) and agents which modulate the innate immune response are consequently accepted to modulate the wound healing process (Browder et al., 1988; Compton et al., 1996; Portera et al., 1997). Interestingly the observed effect of $\beta$-glucans as a nutritional intervention on up-regulating of the growth factor activity pathway is indirectly immune regulatory which was hypothesized beforehand. In addition, Delatte et al (2001) reported that paediatric burns can be effectively treated with glucan-collagen mixtures. In another study, the effects of $(1,3 / 1,6)$ - $\beta$-D-glucan on lung immune development in the neonatal piglet was investigated and showed that $\beta$-glucan reduced the mRNA expression of transforming growth factor (TGF) $\beta 2$ and tended to reduce the mRNA expression of TGF- $\beta 1$ in lung tissue (Thorum et al., 2013). So the effects of dietary $\beta$-glucans on immune responses can be mediated via regulating activities of growth factors. The genes related to anion transmembrane transporter activity in the quercetin and oat hulls included diet were expressed less. Effects of nutritional intervention on regulating gene expression of anion transmembrane transporter activity has been also reported (Lillycrop et al., 2010). Although the effectiveness of the nutritional interventions on regulating gene expression, tested in the current study, was very limited, Xiao et al (2012) indicated in 3-wk old broilers, that were supplemented with mannan-oligosaccharides (MOS) from day-old onwards, a total of 672 deferentially expressed genes (fold change $>1.2$ ) in the jejunum. The expressed genes were involved in diverse biological functions including energy production, cell death, and protein translation. In addition, these authors demonstrated that expression of 77 protein synthesis-related genes was deferentially regulated by MOS in the jejunum, whereas further pathway analysis indicated 15 genes related to oxidative phosphorylation were upregulated in the jejunum, and expression of genes important in cellular stress 
response, such as peroxiredoxin 1, superoxide dismutase 1, and thioredoxin, were also increased by MOS. In addition, differential expression of genes associated with cellular immune processes, including lysozyme, lumican, $\beta$-2-microglobin, apolipoprotein A-1, and fibronectin 1, were observed in MOS-fed broilers. Royan et al (2011) also demonstrated fish oil as a more effective fat in up-regulating hepatic PPARa gene expression in broilers.

It can be concluded that changes in gene sets in the current study seem not to have an obvious relation with immune related processes, except for $\beta$-glucans which affected the gene expression of growth factor activity. The main reason for the observed discrepancy between our data and literature is not clear, but the age of the applied nutritional interventions could be the case. So it seems that nutritional modulation can be more effective when it is applied in post-hatched broilers chicks.

\section{Other immune competence related parameters}

Nutrients are the major decisive factors that determine the expression of genetic potential of birds in terms of growth and immunity (Katanbaf et al., 1988; Klasing and Barnes, 1988). As described below, information in literature is available regarding the modulating effects of the five nutritional interventions tested in the current study on immune responses related parameters

The bursa of Fabricius and thymus are the primary lymphoid organs in which the lymphocyte precursors develop into immune competent native lymphocytes. Secondary lymphoid tissues are the spleen, bone marrow, harderian gland, pineal gland and organised lymphoid tissues (Panda et al., 2015). The highest and lowest weight of bursa as a percentage of body weight was detected in fish oil on $\mathrm{d} 21$ and $\mathrm{d} 28$, respectively. Among treatments, relative weight of spleen was higher in $\mathrm{d} 28$ compared to $\mathrm{d} 21$.

The effects of the five nutritional interventions, used in the current study, on immunity related parameters of birds have been well documented in the literature.

Effect of interventions on bursa weight

In the current study, no effects of nutritional interventions on bursa and spleen weight were observed. In contrast, Wang et al (2000), who investigated the effects of fat source (sunflower oil, SO; animal oil, AO; linseed oil, LO; or menhaden fish oil, FO at 5\%) on immune response of the offspring of the Single Comb White Leghorn laying hens, reported that growths of thymus, spleen, and bursa were significantly impacted by the amount of dietary PUFA, the ratio of $n-6$ to $n-3$ fatty acids, and n- 3 PUFA components. Sridhar et al (2015), who studied dietary incorporation of n-3 PUFA rich vegetable oil sources (soybean oil, SO; mustard oil, MO; linseed oil, LO; and fish oil, FO) on immune response in Krishibro broilers, detected that FO improved the relative bursa weight compared to other nutritional interventions. Ao and Choct (2013) demonstrated that birds given mannan-oligosaccharide tended to have a heavier bursa and lower spleen/bursa weight ratio at $35 \mathrm{~d}$ of age. In the study of Wang et al (2000) however, effects were observed after supplementing omega-3 fatty acids via maternal nutrition or prenatally, whereas in the current study the fatty acids were supplemented in the adult phase.

Effect of interventions on antibody production and immune cells

Hager-Theodorides et al (2014) detected a linear dose-dependent manner of quercetin on IgY antibody production in response to SRBC immunization. Yang et al (2015), who evaluated the effects of EPA, DHA, and a combination of both, on the signalling pathways in lipopolysaccharide (LPS)stimulated intestinal B lymphocytes from broiler chickens, observed that dietary n- 3 PUFA suppressed the LPS stimulated proliferation of B lymphocytes by interfering with phosphatidylinositol signalling and the second messenger pathways. Dietary supplementation of MOS increased mucosal IgA secretions and humoral and cell-mediated immune responses of neonatal chicks (Gomez-Verduzco et al., 2009). Yitbarek et al (2015) who compared the effectiveness of a yeast-derived carbohydrates (YDC), and a blend of YDC and probiotics (Lactobacillus acidophilus, Lactobacillus casei, Streptococcus faecium, Bacillus subtilis), plus YDC as a sort of symbiotic, SNB) in pullets, showed that SNB compared to YDC had a more balanced T-helper (Th)-1/Th-2 response locally, and a more Th-2dependent response systemically. It has been reported that dietary supplementation with yeast products derived from Saccharomyces cerevisiae can modulate both the innate and humoral immune system in broilers (Gao et al., 2008; Muthusamy et al., 2011; Yitbarek et al., 2013).

Although the composition of the yeast-derived components are variable, they essentially are rich sources of s1,3-1,6-glucan, mannan polysaccharides and nucleotides (Lipke and Ovalle, 1998). Yeast cell wall polysaccharides, including $\beta$-glucans and mannan, could act as microbe associated molecular patterns and modulated the immune system through pattern recognition receptors (PRR) (Ferket et al., 2002; Jawhara et al., 2012; Shashidhara and Devegowda, 2003). Modulation of PRR expressed by cells of the innate immune system including macrophages and dendritic cells would be followed by production of cytokines, some of which are involved in B cell development and antibody production (Reise-Sousa, 2004). Gomez-Verduzco et al (2009) demonstrated that supplementation of $0.05 \%$ of yeast cell wall in the diet increased humoral and cell mediated immune response in broiler chickens 
following natural exposure to Eimeria spp. Lowery et al (2005) showed that a diet containing purified $\beta$-glucans induced an innate immune response against Salmonella enterica serovar Enteritidis in immature chickens. In vivo administration of $\beta$-glucans enhanced immune reactions and up-regulate the resistance of host against tumour cells (Kogan, 2000). Furthermore, administration of glucans to macrophages activated by LPS increased production of cytokines like interleukin-1 and TNF-a, which subsequently induced lymphocyte differentiation and proliferation to enhance immune responses (Adachi et al., 1994; Chihara, 1992). Alizadeh et al (2016) reported that dietary supplementation with $0.25 \%$ of yeast cell wall stimulated Th2 cell-mediated immune response indicating the immunomodulatory activities of these products following immunization with non-inflammatory antigens.

Zimmermann et al (2015) demonstrated in vitro dose-dependent cyto-protective and geno-protective effects of $\beta$-glucans on broiler chicken lymphocytes with damaged DNA by aflatoxin B1. A large number of in vitro and in vivo studies support an immuno-modulatory role for quercetin and other flavonoids in man and in rodents (García-Lafuente et al., 2009; González-Gallego et al., 2010; Serafini et al., 2010). Studies on human lymphocytes showed that flavonoids reduced immune cell proliferation and in vitro cytokine production in response to PHA stimulation (Pandey et al., 2005). Yang et al (2015) showed that EPA and DHA suppressed the LPS-stimulated proliferation of B lymphocytes by interfering with phosphatidylinositol signalling and the second messenger pathways. In the current study, the production of antibodies and immune cells were not measured. Based on the information received from the expressed genes, however, there were no indications that immune related processed were affected by the applied interventions during the period of 15 to 28 days of age.

Effect of interventions on intestinal adhesion of pathogens

In broilers, $\beta$-glucan has been shown to be an excellent adjuvant for the avian influenza H5 subtype vaccine, enhancing the vaccine immunogenicity (Le et al., 2011). Mannan-oligosaccharide-bound pathogens were prevented from attaching to intestinal mannose residues (Spring et al., 2000), and mannose blocked the colonization of intestinal pathogens, such as Salmonella spp. and Escherichia coli (Kelly et al., 1994). MOS stimulated intestinal mucosal immunity mostly by acting as a non-pathogenic microbial antigen (Davis et al., 2004a,b).

In the current study, the adhesion of pathogens to intestinal tissue was not determined. 


\section{Conclusions}

Based on results of the present investigation it can be concluded that:

- Supplementing oat hulls and lysozyme resulted in comparison with the control group in a temporary reduction in feed intake and body weight gain during the first week of supplementation. Birds compensated for it during the second week of supplementation, with overall no effects on performance.

- Compared to the control group, litter score improved by feeding oat hulls and fish oil (d28), and oat hulls and lysozyme (d33).

- No significant differences were observed in microbiota composition of jejunum and ileum.

- Nutritional interventions only slightly affected the microbiota composition in jejunum and ileum.

- Compared to the control group, feeding oat hulls resulted in an increased amount of Enterococcaceae in the ileum.

- Changes in gene sets seem not to have an obvious relation with immune related processes, except for $\beta$-glucans which affected the gene expression of growth factor activity.

- Adding lysozyme to feed decreased villus height in jejunum (d28) compared to the control and oat hulls fed birds.

- Feeding oat hulls resulted in an increased villus/crypt ratio, total surface area of villi occupied by goblet cells $\left(\mu \mathrm{m}^{2}\right)$ and total villi surface area $\left(\mu \mathrm{m}^{2}\right)$ in jejunum.

In the current study, five dietary interventions, largely varying in the expected mode of actions to affect immune competence of broilers, were tested in 14-28 d old broilers. Despite the different types of interventions, parameters related to immune competence were only marginally affected by the tested products. It seemed that in this study inclusion of oat hulls, and probably $\beta$-glucans had perspective to improve immune competence. The marginal effects could be related to the age of the birds (14-28 d of age), which might be a less sensitive age for affecting parameters related to immune competence. It is recommended to also evaluate some of the tested interventions, especially dietary inclusion of oat hulls and $\beta$-glucans, in broilers starting at early age. In a follow-up study, the effects of some of the investigated interventions on immune competence will be determined in young broilers under challenged conditions. 


\section{References}

Abergel C, Monchois V, Byrne D, et al. 2007. Structure and evolution of the Ivy protein family, unexpected lysozyme inhibitors in gram-negative bacteria. Proc Natl Acad Sci USA 104:63946399. Callewaert L, Aertsen A, Deckers D, et al. 2008. A new family of lysozyme inhibitors contributing to lysozyme tolerance in gram-negative bacteria. PLoS Path 4: e1000019.

Adachi, Y., Okazaki, M., Ohno, N., \& Yadomae, T. (1994). Enhancement of cytokineproduction by macrophages stimulated with ( $1 \rightarrow 3$ )- $\beta$-D-glucan, grifolan(GRN), isolated from Grifola frondosa. Biological and Pharmaceutical Bulletin, 17,1554-1560.

Ajuyah, A.O.; Cherian G.; Wang Y.; Sunwood, H. and Sim, J.S. 2003. Maternal dietary FA modulate the long-chain n-3 PUFA status of chick cardiac tissue. Lipids, 38: 1257-1261.

Alizadeh M., J. C. Rodriguez-Lecompte, H. Echeverry, G. H. Crow, and B. A. Slominski, 2016. Effect of yeast-derived products and distillers dried grains with solubles (DDGS) on antibody-mediated immune response and gene expression of pattern recognition receptors and cytokines in broiler chickens immunized with T-cell dependent antigens. Poultry Science 00:1-11.

Amend AS, Seifert KA, Bruns TD (2010) Quantifying microbial communities with 454 pyrosequencing: does read abundance count? Molecular Ecology 19, 5555-5565.

Amerah, A. M., V. Ravindran, and R. G. Lentle. 2009. Influence of insoluble fibre and whole wheat inclusion on the performance, digestive tract development and ileal microbiota profile of broiler chickens. Br. Poult. Sci. 50:366-375.

Amerah, A. M., V. Ravindran, R. G. Lentle, and D. G. Thomas. 2007. Feed particle size: Implications on the digestion and performance of poultry. World's Poult. Sci. J. 63:439-455.

Amerah, A. M., V. Ravindran, R. G. Lentle, and D. G. Thomas. 2007. Influence of feed particle size and feed form on the performance, energy utilisation, digestive tract development, and digesta parameters of broiler starters. Poult. Sci. 86:2615-2623.

An, B. K., B. L. Cho, S. J. You, H. D. Paik, H. I. Chang, S. W. Kim, C. W. Yun and C. W. Kang, 2008. Growth Performance and Antibody Response of Broiler Chicks Fed Yeast Derived $\beta$-Glucan and Single-strain Probiotics, Asian-Aust. J. Anim. Sci. 21(7): 1027-1032.

Ao, Z. and M. Choct. 2013. Oligosaccharides Affect Performance and Gut Development of Broiler Chickens. Asian-Aust. J. Anim. Sci. 26(1):116-121.

Arts, M. J. T. J., S. J. Dallinga, H. P. Voss, G. R. M. M. Haenen, and A. Bast. 2004. A new approach to assess the total antioxidant capacity using the TEAC assay. Food Chem. 88:567-570.

Bach Knudsen, K. E. 1997. Carbohydrate and lignin contents of plant materials used in animal feeding. Anim. Feed Sci. Technol. 67:319-338.

Baurhoo, B., P. R. Ferket, and X. Zhao. 2009. Effects of diets containing different concentrations of mannanoligosaccharide or antibiotics on growth performance, intestinal development, cecal and litter microbial populations, and carcass parameters of broilers. Poult. Sci. 88:2262-2272.

Baurhoo, B., L. Phillip, and C. A. Ruiz-Feria. 2007. Effects of purified lignin and mannan oligosaccharides on intestinal integrity and microbial populations in the ceca and litter of broiler chickens. Poult. Sci. 86: 1070-1078.

Bautista-Ortega, J.; Goeger, D.E. and Cherian, G. 2009. Egg yolk omega- 6 and omega-3 fatty acids modify tissue lipid components, antioxidant status, and ex vivo eicosanoid production in chick cardiac tissue. Poult Sci, 88: 1167-1175.

Bedford MR. 2000. Exogenous enzyme in monogastric nutrition: Their current value and future benefits. Anim Feed Sci Technol. 86: 1-13.

Bhagwat, S., D. B. Haytowitz, and J. M. Holden. 2013. USDA database for the flavonoid content of selected foods, Release 3.1., Agricultural Research Service. Nutrient Data Laboratory. Accessed Jan. 2014. http://www.ars.usda.gov/SP2UserFiles/Place/12354500/Data/Flav/Flav3-1.pdf.

Biggs, P., Parsons, C. M., Fahey, G. C. 2007. The effects of several oligosaccharides on growth performance, nutrient digestibilities, and cecal microbial populations in young chicks. Poult. Sci., 86 (11): 2327-2336. 
Bjerrum L, Engberg RM, Leser TD, Jensen BB, Finster K, Pedersen K(2006) Microbial community composition of the ileum and cecum of broiler chickens as revealed by molecular and cellularbased techniques. Poultry Science 85, 1151-1164.

Board, R. G. and Fuller, R. 1974. Non-specific antimicrobial defense of the avian egg, embryo and neonate. Biol. Rev. 49: 15-49.

Boland, J. S., Davidson, P. M. and Weiss, J. 2003. Enhanced inhibition of Escherichia coli O157: H7 by lysozyme and chelators. J. Food Prot. 66: 1783-1789.

Boots, A. W., M. Drent, V. C. J. De Boer, A. Bast, and G. R. M. M. Haenen. 2011. Quercetin reduces markers of oxidative stress and inflammation in sarcoidosis. Clin. Nutr. 30:506-512.

Bou, R.; Guardiola, F.; Tres, A.; Barroeta, A.C. and Codony, R. 2004.Effect of dietary fish oil, alphatocopheryl acetate, and zinc supplementation on the composition and consumer acceptability of chicken meat. Poult Sci, 83: 282-292.

Browder W., Williams D., Lucore P., Pretus H., Jones E., McNamee R., 1988. Effect of enhanced macrophage function on early wound healing. Surgery; 104: 224-30.

Brummer, M., C. Jansen van Rensburg, and C. A. Moran. 2010. Saccharomyces cerevisiae cell wall products: The effects on gut morphology and performance of broiler chickens. S. Afr. J. Anim. Sci. 40: 14- 21 .

Bugla-Ploskonska G, Kiersnowski A, Futoma-Koloch B, Doroszkiewicz W. 2008. Cooperation between lysozyme and complement system in bactericidal action of human serum-is everything already clear? Cent Eur J Immunol 33:37-42.

Burkholder KM, Thompson KL, Einstein ME, Applegate TJ, Patterson JA (2008) Influence of stressors on normal intestinal microbiota, intestinal morphology, and susceptibility to Salmonella enteritidis colonization in broilers. Poultry Science 87, 1734-1741.

Calder, P.C., 2006. Polyunsaturated fatty acids and inflammation. Prostaglandins, Leukotrienes, and Essential Fatty Acids 75, 197-202.

Callewaert L, Michiels CW. 2010. Lysozymes in the animal kingdom. J Biosci (Bangalore) 35:127-160.

Caruso D, Schlumberger O, Dahm C, Proteau JP. 2002. Plasma lysozyme levels in sheatfish Silurus glanis (L.) subjected to stress and experimental infection with Edwardsiella tarda. Aquacult Res 33: 999-1008.

Cermak R, Landgraf S andWolffram S, 2003. The bioavailability of quercetin in pigs depends on the glycoside moiety and on dietary factors. J Nutr 133:2802-2807. 64:1037-1045.

Chae, B.J., Lohakare, J.D., Moon, W.K., Lee, S.L., Park, Y.H., Hahn, T.W., 2006. Effects of supplementation of beta-glucan on the growth performance and immunity in broilers. Res. Vet. Sci. 80, 291-298.

Chang Q, Zuo Z, Chow MSS and HoWKK, 2005. Difference in absorption of the two structurally similar flavonoid glycosides, hyperoside and isoquercitrin, in rats. Eur J Pharm Biopharm 59:549-555.

Chen, J., Seviour, R., 2007. Medicinal importance of fungal b-(1 3), (1 6)-glucans. Mycol. Res. 111, 635-652.

Cheng, Y.H., Lee, D.N., Wen, C.M., Weng, C.F., 2004. Effects of b-glucan supplementation on lymphocyte proliferation, macrophage chemotaxis and specific immune responses in broilers. Asian Australas. J. Anim. Sci. 17: 1145-1149.

Cherian, G. 2011. Essential fatty acids and early life programming in meat type birds. Worlds Poult Sci J, 67: 599-614.

Chihara, G. (1992). Recent progress in immunopharmacology and therapeutic effectsof polysaccharides. Development in Biological Standardization, 77, 191-197.

Choct M, Hughes RJ, Bedford MR(1999) Effects of a xylanase on individual bird variation, starch digestion throughout the intestine, and ileal and caecal volatile fatty acid production in chickens fed wheat. British Poultry Science 40, 419-422.

Ciska E, Kozowska H. 1998. Glucosinolates of cruciferous vegetables. Polish J Food Nutr Sci; 48: 5-22.

Comalada, M., I. Ballester, E. Bailon, J. Xaus, J. Galvez, F. S. DeMedina, and A. Zarzuelo. 2006. Inhibition of pro-inflammatory markers in primary bone marrow-derived mouse macrophages by naturally occurring flavonoids: Analysis of the structure-activity relationship. Biochem. Pharmacol. 72: 1010-1021.

Compton R., Williams D., Browder W., 1996. The beneficial effect of enhanced macrophage function on the healing of bowel anastomoses. Am Surgeon; 62: 14-8.

Cox, C. M., L. H. Stuard, S. Kim, A. P. McElroy, M. R. Bedford, and R. A. Dalloul, 2010. Performance and immune responses to dietary $\beta$-glucan in broiler chicks, Poultry Science 89 :1924-1933. 
Crespy V, Morand C, Besson C, Manach C, Demigne C and Remesy C., 2001. Comparison of the intestinal absorption of quercetin, phloretin and their glucosides in rats. J Nutr 131:2109-2114.

D'Alba L, Shawkey MD, Korsten P, et al. 2010. Differential deposition of antimicrobial proteins in blue tit (Cyanistescaeruleus) clutches by laying order and male attractiveness. Behav Ecol Sociobiol

Davis, M. E., C. V. Maxwell, G. F. Erf, D. C. Brown, and T. J. Wistuba. 2004b. Dietary supplementation with phosphorylated mannans improves growth response and modulates immune function of weanling pigs. J. Anim. Sci. 82:1882-1891.

Davis, M. E., D. C. Brown, C. V. Maxwell, Z. B. Johnson, E. B. Kegley, and R. A. Dvorak. 2004a. Effect of phosphorylated mannans and pharmacological additions of zinc oxide on growth and immunocompetence of weanling pigs. J. Anim. Sci. 82:581-587.

De Boer VCJ, Dihal AA, van der Woude H, Arts ICW, Wolffram S, Alink GM, et al, 2005. Tissue distribution of quercetin in rats and pigs. J Nutr 135: 1617-1618.

Delatte S.J., Evans J., Hebra A., Adamson W., Othersen H. B., Tagge E. P., 2001. Effectiveness of beta-glucan collagen for treatment of partial-thickness burns in children. J Pediatr Surg, 36: 113 8.

DiPietro L. A., 1995. Wound healing: the role of the macrophage and other immune cells. Shock, 4: 233-40.

Downey, R. K., and J. M. Bell. 1990. New developments in canola research. Pages 37-46 in Canola and Rapeseed. Production, Chemistry, Nutrition and Processing Technology. F. Shahidi, ed. Van Nosytand Reinhold, New York, NY.

Durance, T. D. 1994. Separation, purification, and thermal stability of lysozyme and avidin from chicken egg white. Egg uses and processing technologies, new developments, (eds J. S. Sim \& S. Nakai). CAB International, Wallingford, UK. Pp. 77-93.

Ferket, P. R. 2004. Alternatives to antibiotics in poultry production: responses, practical experience and recommendations. Nutritional biotechnology in the feed and food industries: Proceedings of Alltech's 20th Annual Symposium, Kentucky, USA, 56-67.

Ferket, P., C. Parks, and J. Grimes. 2002. Benefits of dietary antibiotic and mannanoligosaccharide supplementation for poultry. Multi-State Poultry Meeting 14.

Figuerola J, Munoz E, Gutierrez R, Ferrer D. 1999. Blood parasites, leucocytes and plumage brightness in the Cirl Bunting, Emberiza cirlus. Funct Ecol 13: 594-601.

Fisher K, Phillips C (2009) The ecology, epidemiology and virulence of Enterococcus. Microbiology 155(Pt 6): 1749-1757.

Fleming, A. 1922. On a remarkable bacteriolytic element found in tissues and secretions. Proceedings of the Royal Society of London. Series B: Biological Sciences 93: 306-317.

Forbes, D. H. Blom, N. Kostomitsopoulos, G. Moore, and G. Perretta. 2007. Euroguide on the accommodation and care of animals used for experimental and other scientific purposes. Royal Society of Medicine Press Limited, London, UK.

Fraher MH, O'Toole PW, Quigley EMM (2012) Techniques used to characterize the gut microbiota: a guide for the clinician. Nature Reviews in Gastroenterology and Hepatology. 9, 312-322.

Franz CM, Huch M, Abriouel H, Holzapfel W, Ga'Ivez A. 2011. Enterococci as probiotics and their implications in food safety. Int J Food Microbiol 151(2): 125-140.

Fritsche, K.L., Cassity, N.A., Huang, S.C., 1991. Effect of dietary fat source on antibody production and lymphocyte proliferation in chickens. Poultry Science 70, 611-617.

Fuller, H. L., and M. Rendon, 1977. Energetic efficiency of different dietary fats for growth of young chicks, Poult. Sci. 56: 549-557.

Futoma-Koloch B, Bugla-Ploskonska G. 2009. The efficiency of the bactericidal action of serum raised by complement and lysozyme against bacteria which avoid the immunological response of higher organisms. Postepy Higieny i Medycyny Doswiadczalnej 63:471-484.

Gabriel, I., S. Mallet, and P. Sibille. 2005. Digestive microflora of bird: Factors of variation and consequences on bird. INRA Prod. Anim. 18: 309-322.

Gao, J., H. J. Zhang, S. H. Yu, S. G. Wu, I. Yoon, J. Quigley, Y. P. Gao, and G. H. Qi, 2008. Effects of Yeast Culture in Broiler Diets on Performance and I mmunomodulatory Functions Poultry Science 87: 1377-1384.

García-Lafuente, A., Guillamón, E., Villares, A., Rostagno, M.A., Martínez, J.A., 2009. Flavonoids as anti-inflammatory agents: implications in cancer andcardiovascular disease. Inflamm. Res. 58, 537-552. 
Gee JM, Wroblewska MA, Bennett RN, Mellon FA and Johnson IT, 2004. Absorption and twenty-fourhour metabolism time-course of quercetin-3-O-glucoside in rats, in vivo. J Sci Food Agric, 84: 1341- 1348.

Geier MS, Torok VA, Allison GE, Ophel-Keller K, Hughes RJ (2009) Indigestible carbohydrates alter the intestinal microbiota but do not influence the performance of broiler chickens. Journal of Applied Microbiology 106, 1540-1548.

Genstat 8 Committee. 2002. Genstat 8 reference manual; release 3. Clarendon Press, Oxford, UK.

Gentleman, R. C., V. J. Carey, D. M. Bates, B. Bolstad, M. Dettling, S. Dudoit, B. Ellis, L. Gautier, Y. Ge, J. Gentry, K. Hornik, T. Hothorn, W. Huber, S. Iacus, R. Irizarry, F. Leisch, C. Li, M. Maechler, A. J. Rossini, G. Sawitzki, C. Smith, G. Smyth, L. Tierney, J. Y. Yang, and J. Zhang. 2004. Bioconductor: Open software development for computational biology and bioinformatics. Genome biol 5: R80

Gentleman, R., V. Carey, S. Dudoit, R. I rizarry, and W. Huber. 2005. Bioinformatics and computational biology solutions using $r$ and bioconductor: Pp. 397-420. , springer (eds), new york.

Gershwin, M., R. Beach and L. Hurley, 1985. The potent impact of nutritional factors on immune

Gibson, G. R., Probert, H. M., Van Loo, J., Rastall, R. A., Roberfroid, M. B. 2004. Dietary modulation of the human colonic microbiota: Updating the concept of prebiotics. Nutr. Res. Rev., 17 (2): 259275.

Goliomytis, M., Tsoureki, D., Simitzis, P.E., Charismiadou, M.A., Hager-Theodorides, A.L., Deligeorgis, S.G., 2014b. The effects of quercetin dietary supplementation on broiler growth performance, meat quality, and oxidative stability. Poult. Sci. 93, 1957-1962.

Gomez-Verduzco, G., A. Cortes-Cuevas, C. Lopez-Coello, E. Avila-Gonz'alez, and G. M. Nava. 2009. Dietary supplementation of mannan-oligosaccharide enhances neonatal immune responses in chickens during natural exposure to Eimeria spp. Acta Vet. Scand. 51: 11.

Gonzalez-Alvarado, J. M., E. Jimenez-Moreno, D. Gonzalez-Sanchez, R. L'azaro, and G. G. Mateos. 2010. Effect of inclusion of oat hulls and sugar beet pulp in the diet on productive performance and digestive traits of broilers from 1 to 42 days of age. Anim. Feed Sci. Technol. 162:37-46.

Gonzalez-Alvarado, J. M., E. Jimenez-Moreno, R. Lazaro, and G. G. Mateos. 2007. Effects of cereal, heat processing of the cereal, and fiber on productive performance and digestive traits of broilers. Poult. Sci. 86: 1705-1715.

González-Gallego, J., García-Mediavilla, M.V., Sánchez-Campos, S., Tu〜nó, M.J., 2010. Fruit polyphenols, immunity and inflammation. Br. J. Nutr. 104, S15-S27.

Gordon HA, Pesti L (1971) The gnotobiotic animal as a tool in the study of host-microbial relationships. Bacteriological Reviews 35, 390-429.

Gunal M, Yayli G, Kaya O, Karahan N, Sulak O (2006) The effects of antibiotic growth promoter, probiotic or organic acid supplementation on performance, intestinal microflora and tissue of broilers. International J ournal of Poultry Science 5, 149- 155.

Guo, Y., R. Ali, and M. Qureshi. 2003. The Influence of $\beta$-Glucan on Immune Responses in Broiler Chicks. Immunopharmacol. Immunotoxicol. 25: 461-472.

Hager-Theodorides, A.L., M. Goliomytis, S. Delis, S. Deligeorgis. 2014. Effects of dietary supplementation with quercetin on broiler immunological characteristics. Animal Feed Science and Technology 198: 224-230.

Hamalainen, M., R. Nieminen, P. Vuorela, M. Heinonen, and E. Moilanen. 2007. Anti-inflammatory effects of flavonoids: genistein, kaempferol, quercetin, and daidzein inhibit STAT-1 and NFkappa B activations, whereas flavone, isorhamnetin, naringenin, and pelargonidin inhibit only NF-kappa B activation along with their inhibitory effect on iNOS expression and NO production in activated macrophages. Mediators of Inflamm. Article ID 45673.

Hammons S, Oh PL, Martinez I, Clark K, Schlegel VL, Sitorius E, Scheideler SE, Walter J (2010) A small variation in diet influences the Lactobacillus strain composition in the crop of broiler chickens. Systematic and Applied Microbiology 33, 275-281.

Haščik, P., Kovač, M. and Hanzlik, K. (1994): Substitution of rapeseed oilcake for soyabean meal during the second feeding phase of broilers. Živočišna Vyroba 39, 1041-1047.

He, X.; Yang, X. and Guo, Y. 2007. Effects of different dietary oil sources on immune function in cyclophosphamide immunosuppressed chickens. Anim Feed Sci Tech, 139: 186-200.

Hetland, H., and B. Svihus. 2001. Effect of oat hulls on performance, gut capacity, and feed passage time in broiler chickens. Br. Poult. Sci. 42:354-361. 
Hetland, H., B. Svihus, and A. Krogdahl. 2003. Effects of oat hulls and wood shaving on digestion in broilers and layers fed diets based on whole or ground wheat. Br. Poult. Sci. 44:275-282.

Hetland, H., B. Svihus, and M. Choct. 2005. Role of insoluble fiber on gizzard activity in layers. J. Appl. Poult. Res. 14:38-46.

Holland MCH, Lambris JD. 2002. The complement system in teleosts. Fish Shellfish Immunol 12:399420.

Hong Y-J and Mitchell AE, 2004. Metabolic profiling of flavonol metabolites in human urine by liquid chromatography and tandem mass spectrometry. J Agric Food Chem 52:6794-6801.

Hooge, D. M. 2004. Meta-analysis of broiler chicken pen trials evaluating dietary mannan oligosaccharide, 1993-2003. Int. J. Poult. Sci. 3:163-174.

Huang, D. W., B. T. Sherman, and R. A. Lempicki. 2009. Systematic and integrative analysis of large gene lists using david bioinformatics resources. Nat. Protoc. 4(1):44-57.

Huang, R. Y., Y. L. Yu, W. C. Cheng, C. N. Ouyang, E. Fu, and C. L. Chu. 2010. Immunosuppressive effect of quercetin on dendritic cell activation and function. J. Immunol. 184:6815-6821.

Hubener K, Jahjen W, Simon O (2002) Bacterial responses to different dietary cereal types and xylanase supplementation in the intestine of broiler chicken. Archives of Animal Nutrition 56, 167187.

Hudalla, G. A. and W. L. Murphy, 2011. Biomaterials that regulate growth factor activity via bioinspired interactions, Adv Funct Mater. 21(10): 1754-1768.

Hulan, H.W.; Ackman, R.G.; Ratnayake, W.M. and Proudfoot, F.G. 1989. Omega-3 fatty acid levels and general performance of commercial broilers fed practical levels of redfish meal. Poult Sci, 68: 153-162.

I brahim HR, Hatta H, Fujiki M, Kim M, Yamamoto T. 1994. Enhanced antimicrobial action of lysozyme against gram-negative and grampositive bacteria due to modification with perillaldehyde. J Agric Food Chem 42:1813-1817.

Iji, P. A., A. A. Saki, and D. R. Tivey. 2001. Intestinal structure and function of broiler chickens on diets supplemented with a mannan oligosaccharide. J. Sci. Food Agric. 81: 1186-1192.

Jawhara, S., K. Habib, F. Maggiotto, G. Pignede, P. Vandekerckove, E. Maes, L. Dubuquoy, T. Fontaine, Y. Guerardel, and D. Poulain. 2012. Modulation of intestinal inflammation by yeasts and cell wall extracts: strain dependence and unexpected antiinflammatory role of glucan fractions. PloS One. 7:e40648.

Jeun-Horng, L.; Yuan-Hui, L. and Chun-Chin, K. 2002. Effect of dietary fish oil on fatty acid composition, lipid oxidation and sensory property of chicken frankfurters during storage. Meat Sci, 60: 161-167.

Jimenez-Moreno, E., A. de Coca-Sinova, J. M. Gonzalez-Alvarado, and G. G. Mateos, 2015. Inclusion of insoluble fiber sources in mash or pellet diets for young broilers. 1. Effects on growth performance and water intake Poultry Science 00:1-12.

Jimenez-Moreno, E., J. M. Gonzalez-Alvarado, A. Gonzalez-Serrano, R. Lazaro, and G. G. Mateos. 2009a. Effect of dietary fiber and fat on performance and digestive traits of broilers from one to twenty-one days of age. Poult. Sci. 88:2562-2574.

Jimenez-Moreno, E., J. M. Gonzalez-Alvarado, R. L'azaro, and G. Mateos G.. 2009b. Effects of type of cereal, heat processing of the cereal, and fiber inclusion in the diet on gizzard $\mathrm{pH}$ and nutrient utilization in broilers at different ages. Poult. Sci. 88: 1925-1933.

Jimenez-Moreno, E., S. Chamorro, M. Frikha, H. M. Safaa, R. Lazaro, and G. G. Mateos. 2011. Effects of increasing levels of pea hulls in the diet on productive performance and digestive traits of broilers from one to eighteen days of age. Anim. Feed Sci. Technol. 168: 100-112.

Jimenez-Moreno, E., M. Frikha, A. de Coca-Sinova, J. Garcia, and G. G. Mateos. 2013a. Oat hulls and sugar beet pulp for broiler diets: 1 . Effects on growth performance and nutrient digestibility. Anim. Feed Sci. Technol. 182:33-43.

Jimenez-Moreno, E., M. Frikha, A. de Coca-Sinova, R.P. Lázaro, G.G. Mateos, 2013b. Oat hulls and sugar beet pulp in diets for broilers. 2. Effects on the development of the gastrointestinal tract and on the structure of the jejunal mucosa. Animal Feed Science and Technology, 182: 44-52.

Johnson, E. A. 1994. Egg-white lysozyme as a preservative for use in foods. Egg uses and processing technologies, new developments, (eds J. S. Sim \& S. Nakai). CAB International, Wallingford, UK. Pp. 177-191. 
Kalmendal, R., K. Elwinger, L. Holm, and R. Tauson. 2011. Highfibre sunflower cake affects small intestinal digestion and health in broiler chickens. Br. Poult. Sci. 18; 52:86-96.

Katanbaf, M.N., Dunnington, E.A. and Siegel, P.B. 1988. Allomorphic relationships from hatching to 56 days in parental lines and F1 crosses of chickens selected over 27 generations for high orlow body weight. Growth Development and Aging 52: 11-22.

Kelley, D.S., Daudu, P.A., 1993. Fat intake and immune response. Progress in Food and Nutrition Science 17, 41-63.

Kelly, D., R. Begbie, and T. P. King. 1994. Nutritional influences on interactions between bacteria and the small intestinal mucosa. Nutr. Res. Rev. 7:233-257.

Khajali, F., Slominski, B.A., 2012. Factors that affect the nutritive value of canola meal for poultry. Poult. Sci. 91, 2564-2575.

Klasing, K.C. and Barnes, D.M. 1988. Decreased amino acid requirements of growing chick due to immunological stress. J ournal of Nutrition 118: 1158-1164.

Klasing, K. C. 1997. Interaction between nutrition and infectious disease. Pages 73-80 in: Diseases of Poultry, B. W. Calnek, ed. I owa State University Press, Ames, IA.

Klasing, K. C. 2007. Nutrition and the immune system. Br. Poult. Sci. 48:529-537.

Klosterbuer, A., Z. F. Roughead, and J. Slavin. 2011. Benefits of dietary fiber in clinical nutrition. Nutr. Clin. Pract. 26(5):625-635.

Knudsen KE. Carbohydrate and lignin contents of plant materials used in animal feeding. Anim Feed Sci Technol 1997; 67: 319-38.

Kocher A, Choct M, Porter MD, Broz J. 2000The effect of enzyme addition to broiler diets containing high concentrations of canola or sunflower meal. Poult Sci; 79: 1767-74.

Kogan, G. (2000). ( $1 \rightarrow 3,1 \rightarrow 6$ )- $\beta$-D-Glucans of yeasts and fungi and their biologicalactivity. Studies in Natural Products Chemistry, 23, 107-152.

Koncicki, A., Krasnodebska-Depta, A., Faruga, A., Mikulski, D., Kozlowski, M., Kozlowska, H., Janowska, I. and Rotkiewicz, D. (1991): Effect of complete feed diets containing various rapeseed meals on selected haematological and biochemical indices in broiler chicks. Zeszyty Naukowe Akademii Rolniczej we Wroclawiu, Weterynaria 48, 97-105.

Koppenol, A., Delezie, E., Aerts, J., Willems, E., Wang, Y., Franssens, L., Everaert, N., Buyse, J., 2014. Effect of the ratio of dietary n-3 fatty acids eicosapentaenoic acid and docosahexaenoic acid on broiler breeder performance, egg quality and yolk fatty acid composition at different breeder ages. Poultry Science 93, 564-573.

Korol, W., Jaskiewicz, T., Bartuzi, G., Bogusz, G., Niescior, H., Grabowski, C. and Mojek, E. (1994): Chemical composition of rape seed from low glucosinolate varieties grown in Poland. J. Anim. Feed Sci. 3, 57-64.

Korver, D.R. 2012. Implications of changing immune function through nutrition in poultry, Animal Feed Science and Technology 173: 54-64.

Korver, D.R. and Klasing, K.C. 1997. Dietary fish oil alters specific and inflammatory immune responses in chicks. J Nutr, 127: 2039-2046.

Kuhn, M., D. Szklarczyk, A. Franceschini, C. von Mering, L. J. Jensen, and P. Bork. 2012. Stitch 3: Zooming in on protein-chemical interactions. Nucleic Acids Res. 40(D1): D876-D880.

Le, T., Le, T., Doan, T.H., Quyen, D., Le, K.X., Pharm, V., Nagataki, M., Nomura, H., I keue, Y., Watanabe, Y., et al., 2011. The adjuvant effect of Sophy b-glucan to the antibody response in poultry immunized by the avian influenza A H5N1 and H5N2 vaccines. J. Microbiol. Biotechnol. 21, 405- 411.

Libao-Mercado, A. J. O., C. L. Zhu, J. P. Cant, H. Lapierre, J. N. Thibault, B. Sève, M. F. Fuller, and C. F. M. De Lange. 2009. Dietary and endogenous amino acids are the main contributors to microbial protein in the upper gut of normally nourished pigs. J. Nutr. 139:1088-1094.

Lillycrop, K. A., J. Rodford, E. S. Garratt, J. L. Slater-Jefferies, K. M. Godfrey, P. D. Gluckman, M. A. Hanson and G. C. Burdge, 2010. Maternal protein restriction with or without folic acid supplementation during pregnancy alters the hepatic transcriptome in adult male rats,. British Journal of Nutrition, 103: 1711-171.

Liu, G.; An, S.; Yuan, J.; Guo Y.; Liu, D.; Chen, H. and Huang, R. 2014. Dietary fish oil and zinc reduced plasma prostaglandin E2 content by inhibiting phospholipase A2 production in broilers. J Poult Sci, 51: 66-70. 
López-Ferrer, S.; Baucells, M.D.; Barroeta, A.C. and Grashorn, M.A. 2001. n-3 enrichment of chicken meat. 1. Use of very long-chain fatty acids in chicken diets and their influence on meat quality: fish oil. Poult Sci, 80: 741-752.

Lowry, V., M. Farnell, P. Ferro, C. Swaggerty, A. Bahl, and M. Kogut. 2005. Purified $\beta$-glucan as an abiotic feed additive upregulates the innate immune response in immature chickens against Salmonella enterica serovar Enteritidis. Int. J. Food. Microbiol. 98:309-318.

Lu J, I dris U, Harmon B, Hofacre C, Maurer JJ, Lee MD (2003) Diversity and succession of the intestinal bacterial communities of the maturing boiler chicken. Applied and Environmental Microbiology 69, 6816-6824.

Lumpkins BS, Batal AB, Lee MD (2010) Evaluation of the bacterial community and intestinal development of different genetic lines of chickens. Poultry Science 89, 1614- 1621.

Manach C, Williamson G, Morand C, Scalbert A and Remesy C, 2005. Bioavailability and bioefficacy of polyphenols in humans. I. Review of 97 bioavailability studies. Am J Clin Nutr 81:230S-242S.

Manach, C., Scalbert, A., Morand, C., Remesy, C., Jimenez, L., 2004. Polyphenols: food sources and bioavailability. Am. J. Clin. Nutr. 79, 727-747.

Maraghi S, Molyneux DH, Wallbanks KR. 2012. Lysozyme activity in the plasma of rodents infected with their homologous trypanosomes. Iran J Parasitol 7:86-90.

Masschalck B, Van Houdt R, Van Haver EGR, Michiels CW. 2001. Inactivation of gram-negative bacteria by lysozyme, denatured lysozyme, and lysozyme-derived peptides under high hydrostatic pressure. Appl Environ Microbiol 67:339-344.

Mateos, G. G., E. Jimenez-Moreno, M. P. Serrano, and R. Lazaro. 2012. Poultry response to high levels of dietary fiber sources varying in physical and chemical characteristics. J. Appl. Poult. Res. 21:156-174.

Mawson, R., R. K. Heaney, Z. Zdunczyk, and H. Kozlowska. 1994. Rapeseed meal glucosinolates and their antinutritional effects. Part 3. Animal growth and performance. Nahrung 38:167-177.

Maxwell MH, Robertson GW. 1998. The avian heterophil leucocyte: a review. Worlds Poult Sci J 54: 155- 178.

Millet S, Bennett J, Lee KA, Hau M, Klasing KC. 2007. Quantifying and comparing constitutive immunity across avian species. Dev Comp Immunol 31: 188-201.

Molina MF, Sanchez-Reus I, Iglesias I and Benedi J, 2003. Quercetin, a flavonoid antioxidant, prevents and protects against ethanolinduced oxidative stress in mouse liver. Biol Pharm Bull 26:13981402.

Mootha VK, Lindgren CM, Eriksson KF, Subramanian A, Sihag S, et al. (2003). PGC-1alpha-responsive genes involved in oxidative phosphorylation are coordinately downregulated in human diabetes. Nat Genet 34: 267-273.

Morales-Lopez, R., E. Auclair, F. Garcia, E. Esteve-Garcia, and J. Brufau, 2009. Use of yeast cell walls; ß-1, 3/1, 6-glucans; and mannoproteins in broiler chicken diets, Poultry Science 88: 601-607.

Mullen W, Boitier A, Stewart AJ and Crozier A, 2004. Flavonoid metabolites in human plasma and urine after the consumption of red onions: analysis by liquid chromatography with photodiode array and full scan tandem mass spectrometric detection. J Chromatogr A 1058: 163- 168.

Mustapić, Z. and Pospišil, M. (1995): Quality of oil and rapeseed meal of new '00' rapeseed cultivars (in Coatian). 11th International Symposium of Technologies for Drying and Storing. Zbornik radova. pp. 66-73.

Muthusamy, N., S. Haldar, T. Ghosh, and M. Bedford. 2011. Effects of hydrolysed Saccharomyces cerevisiae yeast and yeast cell wall components on live performance, intestinal histo-morphology and humoral immune response of broilers. Br. Poult. Sci. 52:694-703.

Newburg, D. S., Oligosaccharides in human milk and bacterial colonization. J. Pediatr. Gastroenterol. Nutr. 2000, 30(Suppl 2), S8- 17.

Ohno N, Morrison DC. 1989. Lipopolysaccharide interaction with lysozyme-binding of lipopolysaccharide to lysozyme and inhibition of lysozyme enzymatic-activity. J Biol Chem 264: 4434-4441.

Orsolić, N., A. H. Knežević, L. Šver, S. Terzić, and I. Bašić. 2004. Immunomodulatory and antimetastatic action of propolis and related polyphenolic compounds. J. Ethnopharmacol. 94:307315.

Palmer KL, Godfrey P, Griggs A, Kos VN, Zucker J, Desjardins C, Cerqueira G, Gevers D, Walker S, Wortman J, Feldgarden M, Haas B, Birren B, Gilmore MS (2012) Comparative genomics of 
enterococci: variation in Enterococcus faecalis, clade structure in E. faecium, and defining characteristics of E. gallinarum and E. casseliflavus. MBio 3(1):e00318-11.

Pandey, R., Maurya, R., Singh, G., Sathiamoorthy, B., Naik, S., 2005. Immunosuppressive properties of flavonoids isolated from Boerhaavia diffusa Linn. Int.Immunopharmacol. 5, 541-553.

Parks, C. W., J. L. Grimes, P. R. Ferket, and A. S. Fairchild. 2001. The effect of mannanoligosaccharides, bambermycins, and virginiamycin on performance of large white male market turkeys. Poult. Sci. 80:718-723.

Parmentier, H.K., Nieuwland, M.G.B., Barwegen, M.B., Kwakkel, R.P., Schrama, J.W., 1997. Dietary unsaturated fatty acids affect antibody responses and growth of chickens divergently selected for humoral responses to sheep red blood cells. Poultry Science 76, 1164-1171.

Pedroso AA, Menten FFM, Lambais MR, Racanicci AMC, Longo FA, Sorbara JOB (2006) Intestinal bacterial community and growth performance of chickens fed diets containing antibiotics. Poultry Science 85, 747-752.

Phillips, D. C. 1966. The three-dimensional structure of an enzyme molecule. Sci. Am. 215: 78-90.

Portera C. A, Love E. J., Memore L., Zhang L., Mueller A., Browder W., 1997. Effect of macrophage stimulation on collagen biosynthesis in the healing wound. Am Surgeon, 63: 125-31.

Qaisrani, S. N., M. M. van Krimpen, R. P. Kwakkel, M. W. A. Verstegen, and W. H. Hendriks, 2015. Diet structure, butyric acid, and fermentable carbohydrates influence growth performance, gut morphology, and cecal fermentation characteristics in broilers, Poultry Science 94:2152-2164.

Qaisrani, S. N., P. C. A. Moquet, M. M. van Krimpen, R. P. Kwakkel, M. W. A. Verstegen, and W. H. Hendriks. 2014. Protein source and dietary structure influence growth performance, gut morphology, and hindgut fermentation characteristics in broilers, Poultry Science 93 : 3053-3064.

Reis e Sousa, C. R. 2004. Activation of dendritic cells: translating innate into adaptive immunity. Curr. Opin. Immunol. 16:21-25.

Rezaei, M., M. A. Karimi Torshizi, and Y. Rouzbehan, 2011. The influence of different levels of micronized insoluble fiber on broiler performance and litter moisture, Poultry Science, 90 :20082012.

Rezaei M., Karimi Torshizi M. A. and Shariatmadari F. 2014. Inclusion of Processed Rice Hulls as Insoluble Fiber in the Diet on Performance and Digestive Traits of Japanese Quails. J. Anim. Sci. Adv. 4(7): 962-972.

Rieder, A., Grimmer, S., Aachmann, F.L., Westereng, B., Kolset, S.O., Knutsen, S.H., 2013. Generic tools to assess genuine carbohydrate specific effects on in vitro immune modulation exemplified by b-glucans. Carbohydr. Polym. 92, 2075-2083.

Rogel, A. M., D. Balnave, W. L. Bryden, and E. F. Annison. 1987. The digestion of wheat starch in broiler chickens. Aust. J. Agric. Res. 38:639-649.

Rosen, G. D. 2007. Holo-analysis of the efficacy of bio-mos in broiler nutrition. Br. Poult. Sci. 48:2126.

Ross, 2014. Ross 308 broiler: Performance Objectives (http://en.aviagen.com/ross-308/)

Rotelli, A.E., Guardia, T., Juárez, A.O., De La Rocha, N.E., Pelzer, L.E., 2003. Comparative study of flavonoids in experimental models of inflammation. Pharmacol. Res. 48, 601-606.

Rowe M, Czirjak GA, Lifjeld JT, Giraudeau M. 2013. Lysozyme-associated bactericidal activity in the ejaculate of a wild passerine. Biol J Linn Soc 109:92-100.

Royan, M., G. Y. Meng, F. Othman, A. Q. Sazili and B. Navidshad. 2011. Effects of Conjugated Linoleic Acid, Fish Oil and Soybean Oil on PPARs ( $a$ \& $y$ ) mRNA Expression in Broiler Chickens and Their Relation to Body Fat Deposits. Int. J. Mol. Sci., 12(12): 8581-8595.

Rozeboom, D. W., D. T. Shaw, R. J. Tempelman, J. C. Miguel, J. E. Pettigrew, and A. Connolly. 2005. Effects of mannan oligosaccharide and an antimicrobial product in nursery diets on performance of pigs reared on three different farms. J. Anim. Sci. 83:2637-2644.

Rupasinghe, H.P.V., Ronalds, C.M., Rathgeber, B., Robinson, R.A., 2010. Absorption and tissue distribution of dietary quercetin and quercetin glycosides ofapple skin in broiler chickens. J. Sci. Food Agric. 90, 1172-1178.

Sacranie A., B. Svihus, V. Denstadli, B. Moen, P. A. Iji, and M. Choct. 2012. The effect of insoluble fiber and intermittent feeding on gizzard development, gut motility, and performance of broiler chickens. Poultry Science 91 :693-700. 
Sadeghi, A., M. Toghyani, and A. Gheisari, 2015 . Effect of various fiber types and choice feeding of fiber on performance, gut development, humoral immunity, and fiber preference in broiler chicks. Poultry Science 94:2734-2743.

Saki, A. A., H. R. H. Matin, P. Zamani, M. M. Tabatabai, and M. Vatanchian. 2011. Various ratios of pectin to cellulose affect intestinal morphology, DNA quantitation, and performance of broiler chickens. Livest. Sci. 139:237-244.

Saki, A.A. and Hemati Matin, H.R. 2011. Does nutrition help to alleviate sudden death syndrome in broiler chicken? An Overview. Global Vet, 6: 262-268.

Salton, M. R. J. 1957. The properties of lysozyme and its action on microorganisms. Bacteriol. Rev. 21: 82-98.

Searle, L. E., Cooley, W. A., Jones, G., Nunez, A. et al., Purified galactooligosaccharide, derived from a mixture produced by the enzymic activity of Bifidobacterium bifidum, reduces Salmonella enterica serovar Typhimurium adhesion and invasion in vitro and in vivo. J. Med. Microbiol. 2010, 59(Pt 12), 1428-1439.

Sentandreu, R., and D. H. Northcote. 1968. The structure of a glycopeptide isolated from the yeast cell wall. Biochem. J. 109:419-432.

Sentandreu, R., and D. H. Northcote. 1969. Yeast cell-wall synthesis. Biochem. J. 115: 231-240.

Shannon, P. T., D. J. Reiss, R. Bonneau, and N. S. Baliga. 2006. The gaggle: An open-source software system for integrating bioinformatics software and data sources. BMC Bioinformatics 7: 13.

Shashidhara, R., and G. Devegowda. 2003. Effect of dietary mannan-oligosaccharide on broiler breeder production traits and immunity. Poult. Sci. 82:1319-1325.

Shikha Bhatia, P. Nagendra Prabhu, Ann C. Benefiel, Michael J. Miller, JoMay Chow,Steven R. Davis and H. Rex Gaskins, Galacto-oligosaccharides may directly enhance intestinal barrier function through the modulation of goblet cells, Mol. Nutr. Food Res. 2015, 59, 566-573.

Shoaf, K., Mulvey, G. L., Armstrong, G. D., Hutkins, R. W., Prebiotic galactooligosaccharides reduce adherence of enteropathogenic Escherichia coli to tissue culture cells. Inf. Immun. 2006, 74, 6920-6928.

Sijben, J.W.C., Nieuwland, M.G.B., Kemp, B., Parmentier, H.K., Schrama, J.W., 2001. Interactions and antigen dependence of dietary n-3 and n- 6 polyunsaturated fatty acids on antibody responsiveness in growing layer hens. Poultry Science 80, 885-893.

Sims, M. D., K. A. Dawson, K. E. Newman, P. Spring, and D. M. Hoogell. 2004. Effects of dietary mannan oligosaccharide, bacitracin methylene disalicylate, or both on the live performance and intestinal microbiology of turkeys. Poult. Sci. 83: 1148-1154.

Soundararajan R, Wishart AD, Rupasinghe HPV, Arcellana-Panlilio M, Nelson CM, Mayne M, 2008. Quercetin 3-glucoside protects neuroblastoma ( $\mathrm{SH}-\mathrm{SY} 5 \mathrm{Y}$ ) cells in vitro against oxidative damage by inducing sterol regulatory element-binding protein-2-mediated cholesterol biosynthesis. J Biol Chem. 283: 2231-2245.

Spencer JPE, Kuhnle GGC, Williams RJ and Rice-Evans C, 2003. Intracellular metabolism and bioactivity of quercetin and its in vivo metabolites. Biochem J 372:173-181.

Spring, P., C. Wenk, K. A. Dawson, and K. E. Newman. 2000. The effects of dietary mannaoligosaccharides on cecal parameters and the concentrations of enteric bacteria in the ceca of Salmonella challenged broiler chicks. Poult. Sci. 79:205-211.

Squires, E.J . and Summers, J.D. 1993. A consideration of comparative metabolic aspects of the aetiology of sudden death syndrome and ascites in broilers. Brit Vet J, 149: 285-294.

Sridhar K., K. N. Nalini, P. A. Kumar, J. Narasimha, T. Raghunandan and R. V. Ravinder, 2015. Effect of Dietary Incorporation of Omega-3 PUFA Rich Oil Sources on Performance, Carcass Traits, Serum Biochemical Parameters and Immune Response in Krishibro Broilers. Indian Journal of Animal Nutrition, 32(4): 405-409.

Stanley, V. G., C. Brown, and A. E. Sefton. 2000. Comparative evaluation of a yeast culture, mannanoligosaccharide and an antibiotic on performance of turkeys. Poult. Sci. 79(Suppl. 1): 117. (Abstr.)

Stelzer, G., A. Inger, T. Olender, T. Iny-Stein, I. Dalah, A. Harel, M. Safran, and D. Lancet. 2009. Genedecks: Paralog hunting and gene-set distillation with genecards annotation. Omics 13(6) : 477-487.

Sternberg, Z., K. Chadha, A. Lieberman, D. Hojnacki, A. Drake, P. Zamboni, P. Rocco, E. Grazioli, B. Weinstock-Guttman, and F. Munschauer. 2008. Quercetin and interferon- $\beta$ modulate immune 
response(s) in peripheral blood mononuclear cells isolated from multiple sclerosis patients. Journal of Neuroimmunology, 205 (1-2): 142-147.

Subramanian, A., P. Tamayo, V. K. Mootha, S. Mukherjee, B. L. Ebert, M. A. Gillette, A. Paulovich, S. L. Pomeroy, T. R. Golub, E. S. Lander, and J. P. Mesirov. 2005. Gene set enrichment analysis: A knowledge-based approach for interpreting genome-wide expression profiles. Proc. Natl. Acad. Sci. U. S. A. 102(43): 15545-15550.

Svihus, B. 2011. The gizzard: Function, influence of diet structure, and effects on nutrient availability. World's Poult. Sci. J. 67:207-223.

Talbott, S. M., 2012. Baker's Yeast Beta-Glucan Supplement Reduces Upper Respiratory Symptoms and Improves Mood State in Stressed Women, Journal of the American College of Nutrition, 31 (4): 295-300.

Taylor, P.R., Brown, G.D., Reid, D.M., Willment, J.A., Martinez-Pomares, L., Gordon, S., Wong, S.Y.C., 2002. The b-glucan receptor, dectin-1, is predominantly expressed on the surface of cells of the monocyte/macrophage and neutrophil lineages. J. Immunol. 169, 3876-3882.

Teirlynck, E., L. Bjerrum, V. Eeckhaut, G. Huygebaert, F. Pasmans, F. Haesebrouck, J. Dewulf, R. Ducatelle, and F. Van Immerseel. 2009. The cereal type in feed influences gut wall morphology and intestinal immune cell infiltration in broiler chickens. Br. J. Nutr. 102:1453-1461.

Thorum, S. C., S. N. Hester, S. S. Comstock, M H. Monaco, B D. Pence, J. A. Woods, S. M. Donovan, 2013. Dietary $(1,3 / 1,6)$ - $\beta$-D-glucan decreases transforming growth factor $\beta$ expression in the lung of the neonatal piglet. Nutrition Research 33: 322-331.

Torok VA, Hughes RJ, Mikkelsen LL, Perez-Maldonado R, Balding K, MacAlpine R, Percy NJ, OphelKeller K (2011b) Identification and characterization of potential performance-related gut microbiotas in broiler chickens across various feeding trials. Applied and Environmental Microbiology 77, 5868-5878.

Torok VA, Hughes RJ, Ophel-Keller K, Ali M, MacAlpine R (2009) Influence of different litter materials on cecal microbiota colonization in broiler chickens. Poultry Science 88, 2474-2481.

Torok, V. A., C. Dyson, A. McKay and K. Ophel-Keller, 2013. Quantitative molecular assays for evaluating changes in broiler gut microbiota linked with diet and performance. Animal Production Science, 53: 1260-1268.

van der Hoeven-Hangoor, E., C. J. Rademaker, N. D. Paton, M. W. A. Verstegen, and W. H. Hendriks. 2014. Evaluation of free water and water activity measurements as functional alternatives to total moisture content in broiler excreta and litter samples. Poult. Sci. 93:1782-1792.

van der Hoeven-Hangoor, E., C. J. Rademaker, N. D. Paton, M. W. A. Verstegen, and W. H. Hendriks. 2014. Evaluation of free water and water activity measurements as functional alternatives to total moisture content in broiler excreta and litter samples. Poult. Sci. 93: 1782-1792.

van der Klis, J. D., and L. de Lange. 2013. Water intake in poultry. Proc. 19th European Poult. Nutr. Symp., Postdam, Germany, pp. 102-107.

Van Loo, J. 2004. The specificity of the interaction with intestinal bacterial fermentation by prebiotics determines their physiological efficacy. Nutr. Res. Rev., 17 (1): 89-98.

Waage, K. S., and A. P. Hedin. 1985. Quercetin 3-O-galactosyl-( $1 \rightarrow 6)$-glucoside, a compound from narrowleaf vetch with antibacterial activity. Phytochemistry 24:243-245.

Wang $L$ and Morris ME, 2005. Liquid chromatography-tandem mass spectroscopy assay for quercetin and conjugated quercetin metabolites in human plasma and urine. J Chromatogr B 821:194-201.

Wang, Y.W., Ajuyah, A.O., Sunwoo, H.H., Cherian, G., Sim, J.S., 2002. Maternal dietary n-3 fatty acids alter the spleen fatty acid composition and bovine serum albumin-induced wing web swelling in broilers. Poultry Science 81, 1722-1727.

Wang, Y.W., Field, C.J., Sim, J.S., 2000. Dietary polyunsaturated fatty acids alter lymphocyte subset proportion and proliferation, serum immunoglobulin $\mathrm{G}$ concentration, and immune tissue development in chicks. Poultry Science 79, 1741-1748.

Wei, D., D. Williams, W. Browder, Activation of AP-1 and SP1 correlates with wound growth factor gene expression in glucan-treated human fibroblasts, 2002. I nternational I mmunopharmacology 2: $1163-1172$.

Wellman-Labadie O, Picman J, Hincke MT. 2007. Avian antimicrobial proteins: structure, distribution and activity. Worlds Poult Sci J 63:421-438.

Wetscherek, W., Lettner, F., Steinwideer, A. and Lorenz, T. (1993): Rapeseed by-products in poultry finisher diets. Forderungsdienst 41, 320-325. 
Wilms LC, Holman PCH, Boots AW and Kleinjans JCS, 2005. Protection by quercetin and quercetin-rich fruit juice against induction of oxidative DNA damage and formation of BPDE-DNA adducts in human lymphocytes. Gen Toxicol Environ Mutagen 582: 155-162.

Xiao, R., R. F. Power, D. Mallonee, K. Routt, L. Spangler, A. J. Pescatore, A. H. Cantor, T. Ao, J. L. Pierce, and K. A. Dawson. 2012. Effects of yeast cell wall-derived mannan-oligosaccharides on jejunal gene expression in young broiler chickens. Poultry Science 91 : 1660-1669.

Yalcinkaya, H., Gungori, T., Bafialani, M., Erdem, E. 2008. Mannan-oligosaccharides (MOS) from Saccharomyces cerevisiae in broilers effects on performance and blood biochemistry. Turk. J. Vet. Anim. Sci., 32 (1): 43-48.

Yang X., Y. Wang, J. Yao and X. Yang, 2015. Mechanistic study of signalling pathways in intestinal B lymphocytes using eicosapentaenoic and docosahexaenoic acid in broiler chickens, Food and Agricultural Immunology, (27) 3: 329-337.

Yang, X.; Guo, Y.; He, X.; Yuan, J.; Yang, Y. and Wang, Z. 2008. Growth performance and immune responses in chickens after challenge with lipopolysaccharide and modulation by dietary different oils. Animal, 2: 216-223.

Yang, X.; Zhang, B.; Guo, Y.; Jiao, P. and Long, F. 2010. Effects of dietary lipids and Clostridium butyricum on fat deposition and meat quality of broiler chickens. Poult Sci, 89: 254-260.

Yang, Y., P. A. Iji, A. Kocher, L. L. Mikkelsen, and M. Choct. 2008. Effects of mannanoligosaccharide and fructooligosaccharide on the response of broilers to pathogenic Escherichia coli challenge. Br. Poult. Sci. 49: 550-559.

Yin Y, Lei F, Zhu L, Li S, Wu Z, Zhang R, Gao GF, Zhu B, Wang X (2010) Exposure of different bacterial inocula to newborn chicken affects gut microbiota development and ileum gene expression. The ISME Journal 4, 367-376.

Yitbarek A., H. Echeverry, P. Munyaka, and J. C. Rodriguez-Lecompte. 2015. Innate immune response of pullets fed diets supplemented with prebiotics and synbiotics, Poultry Science 94: 1802-1811.

Yitbarek, A., J. Rodriguez-Lecompte, H. Echeverry, P. Munyaka, N. Barjesteh, S. Sharif, and G. Camelo-Jaimes. 2013. Performance, histomorphology, and Toll-like receptor, chemokine, and cytokine profile locally and systemically in broiler chickens fed diets supplemented with yeastderived macromolecules. Poult. Sci. 92:2299-2310.

Young, M., M. J. Davies, D. Bailey, M. J. Gradwell, B. Smestad-Paulsen, J. K. Wold, R. M. Barnes, and E. F. Hounsell. 1998. Characterization of oligosaccharides from an antigenic mannan of Saccharomyces cerevisiae. Glycoconj. J. 15:815-822.

Zhang G., ABF Greg F. Mathis, C Charles L. Hofacre, D Parastoo Yaghmaee, A Richard A. Holley, E and Tim D. Durance, 2010. Effect of a Radiant Energy-Treated Lysozyme Antimicrobial Blend on the Control of Clostridial Necrotic Enteritis in Broiler Chickens. AVIAN DISEASES 54: 1298- 1300.

Zhou Z,WuL, Deng Y, Zhi X, Jiang YH, Tu Q, Xie J, van Nostrand JD, He Z, Yang Y (2011) Reproducibility and quantitation of amplicon sequencing-based detection. The ISME Journal 5, 1303-1313.

Zhu XY, Zhong TZ, Pandya Y, J oerger RD (2002) 16S rRNA-based analysis of microbiota from the cecum of boiler chickens. Applied and Environmental Microbiology 68, 124-137.

Zimmermann, C.E.P., I.B.M. Cruz, F.C. Cadoná, A.K. Machado, C. Assmann, K.B. Schlemmer, R.A. Zanette, D.B.R. Leal, J.M. Santurio. 2015. Cytoprotective and genoprotective effects of b-glucans against aflatoxin B1-induced DNA damage in broiler chicken lymphocytes. Toxicology in Vitro, 29: 538-543. 


\section{Appendix $1 \quad$ Calculated composition of the diets}

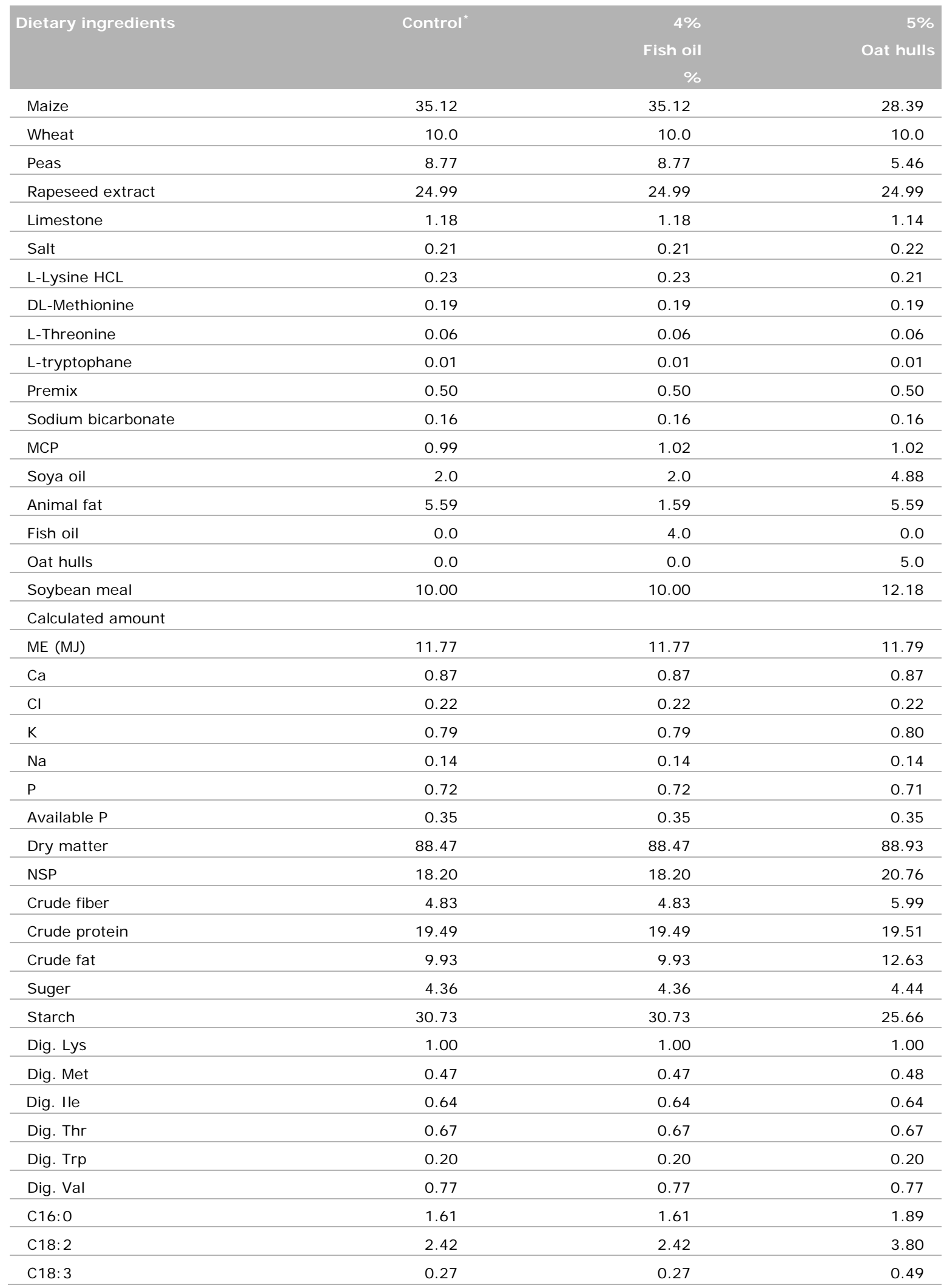




\section{Appendix 2 Calculated composition of the starter and finisher diets}

\begin{tabular}{|c|c|c|}
\hline Dietary ingredients & Starter & Finisher \\
\hline Maize & 62.02 & 25.00 \\
\hline Soybean meal & 32.23 & 19.64 \\
\hline Wheat & - & 43.61 \\
\hline Rapeseed extract & 0.24 & 5.00 \\
\hline Soya oil & 1.50 & 1.20 \\
\hline Limestone & 1.61 & 1.06 \\
\hline Monocalcuum phosphate & 0.86 & 0.18 \\
\hline RDS Premix broiler $5 \%$ & 0.50 & 0.50 \\
\hline L-Lysine HCL 79\% & 0.21 & 0.24 \\
\hline DL-Methionine 99\% & 0.29 & 0.20 \\
\hline L-Threonine 98\% & 0.07 & 0.07 \\
\hline Sodium bicarbonate & 0.17 & 0.17 \\
\hline Salt- $\mathrm{NaCl}$ & 0.23 & 0.19 \\
\hline Xylanase & - & 0.01 \\
\hline Phytase & 0.05 & 0.05 \\
\hline Salinocox $12 \%$ & 0.06 & - \\
\hline \multicolumn{3}{|l|}{ Calculated amount } \\
\hline Moisture & 11.90 & 11.80 \\
\hline ME (MJ) & 12.44 & 12.94 \\
\hline $\mathrm{Ca}$ & 0.86 & 0.55 \\
\hline $\mathrm{Cl}$ & 0.23 & 0.23 \\
\hline $\mathrm{K}$ & 0.91 & 0.76 \\
\hline $\mathrm{Na}$ & 0.14 & 0.15 \\
\hline$P$ & 0.55 & 0.40 \\
\hline Crude fiber & 2.71 & 2.97 \\
\hline Crude protein & 21.21 & 18.66 \\
\hline Crude fat & 5.02 & 6.73 \\
\hline Ash & 5.64 & 4.18 \\
\hline Starch-Am & 39.19 & 41.08 \\
\hline Starch-Ew & 41.75 & 43.46 \\
\hline dlys-P \% & 1.15 & 0.95 \\
\hline vMethP/vLys.-P & 0.50 & 0.48 \\
\hline vCyst-P/vLys.-P & 0.24 & 0.29 \\
\hline vM+CP/vLys. $-\mathrm{P}$ & 0.74 & 0.76 \\
\hline vThreoP/vLys.-P & 0.65 & 0.65 \\
\hline vTryP/vLys.-P & 0.19 & 0.20 \\
\hline Synth.Lys/vLys.-P \% & 14.50 & 19.90 \\
\hline
\end{tabular}




\section{Appendix 3 Chemical and nutritional composition of the rapeseed extract used in the present experiment comparing with canola meal}

(Khajali and Slominski, 2012)

\begin{tabular}{lrr} 
Component & Rapeseed extract & Canola meal \\
ME (Kcal/Kg) & 1384 & 2000 \\
\hline Crude protein & 33.5 & 36.5 \\
\hline Ether extract & 2.6 & 3.6 \\
\hline Dry matter & 87.3 & 90 \\
\hline Crude fiber & 12.0 & 11.6 \\
\hline ADF & 29.2 & 18.2 \\
\hline NDF & 19.4 & 26.0 \\
\hline NSP & 35.2 & 18.0 \\
\hline Sugars & 9.0 & 8.6 \\
\hline Starch & 6.1 & 2.4 \\
\hline Lignin and polyphenoles & & 10.4 \\
\hline Glycoproteins & & 3.3 \\
\hline Glucosinolates $(\mu \mathrm{mol} / g)$ & & 5.5 \\
\hline Ash & 6.7 & 6.8 \\
\hline Ca & 0.74 & 0.67 \\
\hline Available P & 0.36 & 0.38 \\
\hline Arginine & & 2.04 \\
\hline Lysine & 1.8 & 2.0 \\
\hline Threonine & 1.47 & 1.57 \\
\hline Methionine & 0.67 & 0.74 \\
\hline Cystine & 0.84 & 0.85 \\
\hline Tryptophan & 0.44 & 0.48 \\
\hline
\end{tabular}



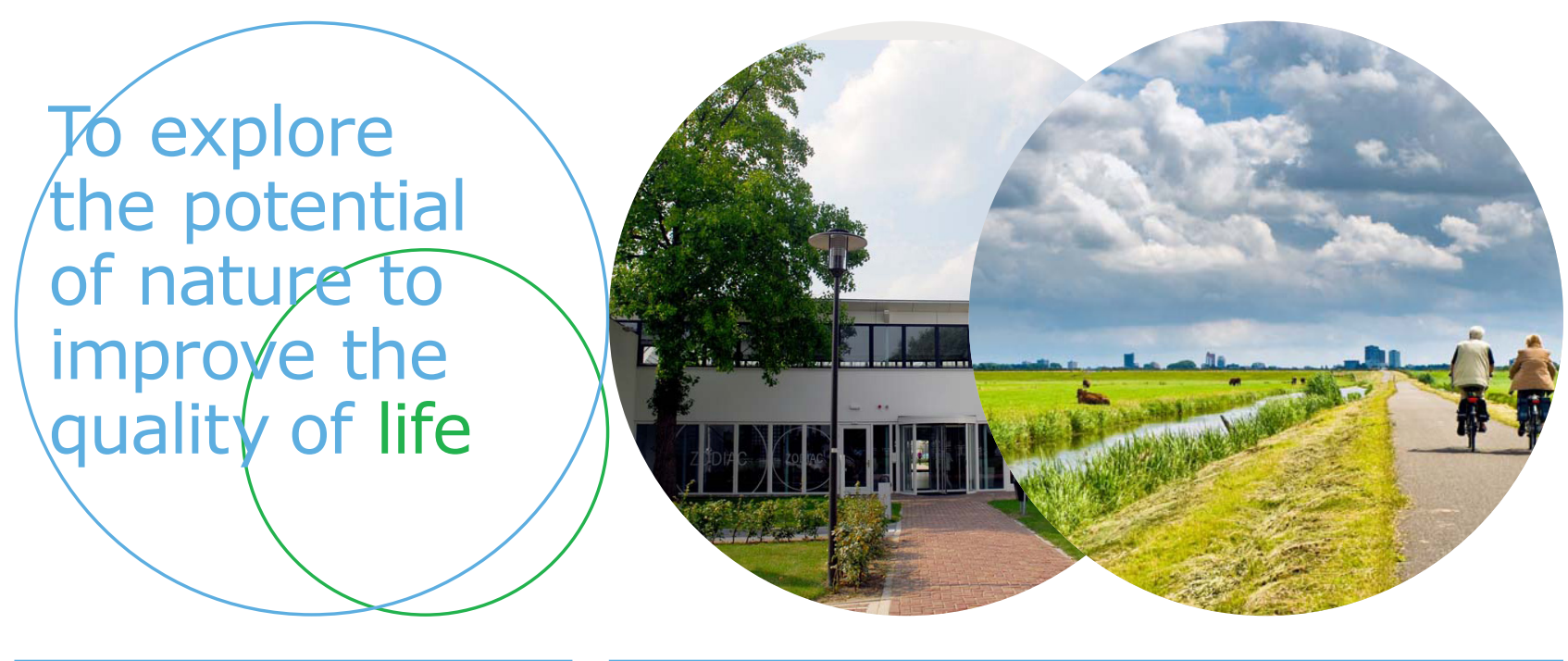

Wageningen Livestock Research P.O. Box 338

$6700 \mathrm{AH}$ Wageningen

The Netherlands

T +31 (0)317483953

E info.livestockresearch@wur.nl

www.wur.nl/livestock-research
Together with our clients, we integrate scientific know-how and practical experience to develop livestock concepts for the 21st century. With our expertise on innovative livestock systems, nutrition, welfare, genetics and environmental impact of livestock farming and our state-of-the art research facilities, such as Dairy Campus and Swine Innovation Centre Sterksel, we support our customers to find solutions for current and future challenges.

The mission of Wageningen University \& Research is 'To explore the potential of nature to improve the quality of life'. Within Wageningen University, nine specialised research institutes of the DLO Foundation have joined forces with Wageningen University to help answer the most important questions in the domain of healthy food and living environment. With approximately 30 locations, 6,000 members of staff and 10,000 students, Wageningen UR is one of the leading organisations in its domain worldwide. The integral approach to problems and the cooperation between the various disciplines are at the heart of the unique Wageningen Approach. 